\title{
Parametric Study for Devulcanization of Waste Tire Rubber Utilizing Deep Eutectic Solvent (DES)
}

\author{
Rashmi Walvekar ${ }^{1, *}$ Kishen Kunju $^{1}$, Ricky Saputra ${ }^{1, \dagger}$, Khalid Siddiqui ${ }^{2}$ and Suganti \\ Ramarad $^{3}$ \\ ${ }^{1}$ School of Engineering, Taylor's University, 47500 Subang Jaya, Selangor, Malaysia \\ ${ }^{2}$ Graphene \& Advanced 2D Materials Research Group (GAMRG), Research center for nano- \\ materials and energy technology (RCNMET), School of science and technology, Sunway University, \\ Subang Jaya, Selangor, Malaysia \\ ${ }^{3}$ School of Engineering and Physical Sciences, Herriotwatt University Malaysia, 62200 Putrajaya, \\ Malaysia
}

\begin{abstract}
Waste rubber is a polymeric material containing $50 \%$ of rubber and is generally referred to as waste tyre rubber. The main purpose of this research is to study ultrasonic devulcanisation of waste rubber utilising deep eutectic solvent (DES) of $\mathrm{ZnCl}_{2}:$ Urea by improving process parameters such as sonication time, reaction temperature and rubber: DES mass ratio by effectively cleaving cross-link sulphur bonds. DES was created and prepared by mixing $\mathrm{ZnCl}_{2}$ with urea at 2:7 and 1:4 molar ratios respectively. Physicochemical properties of the prepared DES was measured using DSC, KFT and TGA analysis to find the freezing point, moisture content and degradation temperature, whereby their freezing point below $60^{\circ} \mathrm{C}$, moisture content lower than $3.0 \mathrm{wt} . \%$ and $200^{\circ} \mathrm{C}$ degradation temperature average. Rubber to DES mass ratio was varied at 1:20, 1:30 and 1:40 and sonicated for 15 minutes inside ultrasonic water-bath. Samples were placed onto hot plate whereby heating temperature was varied at room temperature, $130^{\circ} \mathrm{C}, 150^{\circ} \mathrm{C}$, and $180^{\circ} \mathrm{C}$ for 15 minutes. Samples were filtered, washed with distilled water and dried in oven for 24 hours. Once dried, samples were taken for analysis using TGA, EDX, FESEM, FTIR and Gel content. Under TGA analysis, most samples have an average degradation temperature of $200^{\circ} \mathrm{C}$, hence justifying a successful devulcanisation. EDX analysis shows two occurrences during devulcanisation process which is bond reformation and cleavage. Furthermore, it is determined that heating temperature of $130^{\circ} \mathrm{C}$ is an important parameter as it is the optimum temperature for $\mathrm{ZnCl}_{2}$ :Urea. Under FTIR analysis, it shows that disulphide bond, S-S is the only bond that is being broken while the rest still remains the same. Gel content analysis showed that samples have a lower soluble fraction after devulcanisation process. Finally, FESEM proves that at $130^{\circ} \mathrm{C}$ and 15
\end{abstract}

\footnotetext{
${ }^{*}$ Corresponding author: rashmi.walvekar@gmail.com
} 
minutes is the optimum temperature and time which is illustrated by the smooth surface at that particular point.

\section{Introduction}

Rubber is a form of elastic and flexible substance which is able to elastically deform through a certain applied force. It mainly composed of polymers exhibiting a long-chain carbon bond, rotating around its axis and twisting the chains into different combinations. Main source of rubber originates from rubber tree known as Hevea Brasiliensis [1] which grows sufficiently well under cultivation.

Oils, fillers and antioxidants are compounded together with raw rubber to increase the tensile strength of the rubber's life cycle. In order to utilize raw rubber, it needs to be vulcanised in order to increase the rubber's strength and life as well as reducing manufacturing cost. Only after that, vulcanisation rubber process is carried out. It is an irreversible process in which rubber molecules is cross-linked to the sulphur compound, resulting in tires being elastic and strong resistant to bio-degradation and high temperature [2].

In the manufacturing sector, rubber is considered to be the largest component in composing a tire to where it is broadly applied. Throughout the years, demand for rubber has been ever increasing globally from household applications to industrial fields such as gloves, shoes, insulators and especially on tyres. And with the increasing demand of tyres, the number of vehicles on the road has been increasing drastically. This leads to the around 800 million tires being disposed annually and it is said to increase by $2 \%$ every year [3]. 1.3 billion tires are produced globally which is equivalent to nearly 17 million tonnes per year of used tires as reported by Sienkiewicz et al. [4] which will ultimately lead the wastage of rubber tyres.

Waste rubber is a polymeric material containing $50 \%$ of rubber in tyres and is generally referred to as waste tyre rubber [5]. There is a large amount of vulcanized residue that comes from the production of rubber materials and it considered to be a major problem. Less efforts were taken into recycling them even after their life cycle has ended, resulting in these tyres being wasted to a point where it becomes a pollution source. This is due to the fact that the rubber tyre has a complex microstructure of a three dimensional cross-linking bonds which makes the material not so easily decomposed and insoluble [5].

Therefore to reduce wastage of rubber tyres, different methods of devulcanisation has been introduced. Devulcanisation method is one of the ways to reduce the impact risks on environment by transforming tyres back into virgin rubber or original rubber that can be used for re-vulcanisation purposes. Rubber with a complex structure of three-dimensional network arrangement has carbon-sulphur (-C-S-) bond and sulphur-sulphur (-S-S-) bond attached to it. This -C-S- bond is longer compared to -C-C- bond as sulphur is much larger than carbon. During the devulcanisation process, -C-S- and -S-S- bonds are broken down resulting in a three dimensional structure to obtain plasticity whereby -C-S- bond is broken down under the presence of high temperature, where it gains enough energy to in order to break the -C-S- bond. It is then re-vulcanised again by heating to $120-150^{\circ} \mathrm{C}$ to form better products.

Some of the currently available methods used for devulcanisation are microwave heating [7], continuous ultrasonic [8], microbial action [9], and many other methods. These methods used are definitely capable for devulcanisation of rubber material, however up to a certain limit. This is due to the fact that few of the solvents used before this are not suitable as it is costly and hazardous. In addition to that, end product from using from those 
methods mentioned has a poor mechanical strength which is not ideal for re-vulcanisation process.

Recent study carried out by V. V. Rajan et al. [11] shows experimental analysis where ionic liquid (IL) was used as a solvent for devulcanisation of rubber through microwave irradiation method and it showed positive results. Devulcanisation of rubber tyre was carried out with the combination of microwave radiation and IL which achieved to $50 \%$ removal of sulphur. However, further research found that ionic liquids was not very convenient to be used due to its limitations whereby it has high toxicity level, poor degradability, combustible material and not to mention highly cost. Therefore, these limitations can be avoided by finding a more suitable candidate to replace ILs.

One of the emerging alternative solvent which shows similar properties to ILs is known to be Deep Eutectic Solvent (DES). It's been proven that ILs is able to devulcanise waste tyre rubber and with that justifies DES is an excellent alternative to IL which can devulcanise the waste tyre rubber whilst avoiding all the limitations and problems encountered. It is a mixture of two or more components having a lower melting point than each individual component. By mixing ammonium halide salt which is a hydrogen bond acceptor (HBA) and hydrogen bond donor (HBD) molecule, DES is obtained, resulting in significant decrease in freezing point. Since it has similar properties to ILs such as easy regeneration and non-flammable, it shares similar advantages as well in terms of low vapour pressure, biodegradability, chemical stability, cheap material and easily obtained [13]. Thus, DES is considered as a green solvent in being an important alternative to volatile organic solvents.

Similar research area [12] has been done within the petrochemical industry whereby for desulphurisation process, DES was used to remove sulphur from petrochemical products such as oil. Based on the research done by Wang, Liu, Li et al. [10], it was found that the removal efficiency of sulphur is as high as $99.48 \%$ which further proves that DES is a suitable solvent in removing sulphur and it can be used for devulcanisation process.

Many different combinations of HBA and HBD have been performed since the first experimental analysis of DES was reported. One of the common combinations is with choline chloride, $\mathrm{ChCl}$ and zinc chloride, $\mathrm{ZnCl}_{2}$ salt with other types of $\mathrm{HBDs}$ such as urea. $\mathrm{ChCl}$ salt is commonly picked because it is low in cost and toxicity, biodegradable, and its biocompatibility [10]. On the other hand, zinc chloride, $\mathrm{ZnCl}_{2}$ is chosen due to its biocompatibility and biodegradability of the salt [10].

Hence, currently new approach for devulcanisation process using the DES alongside with ultrasonic treatment under controlled condition of temperature and sonication of water bath was introduced. With the use of DES as a cheaper and greener solvent, this can help reduce energy consumption during the devulcanisation process as well improving its recovery process. Thus, for the interest of the study, the chosen DES used alongside ultrasonic devulcanisation of rubber samples is $\mathrm{ZnCl}_{2}$ :Urea at various molar ratios of 1:4 and $2: 7$.

This study aims to synthesize and characterize $\mathrm{ZnCl}_{2}$ :Urea as a deep eutectic solvents (DESs) of a various molar ratio and to optimise the sonication time, heating temperature and rubber:DES mass ratio on devulcanisation of the waste rubber.

\section{Methodology}

Based on the research project that will be carried out, quantitative study will be used throughout the entire project to which the justification would be made based on the removal amount of sulphur from waste tyre rubber sample during devulcanisation process. 


\subsection{DES preparation samples}

The selection and synthesis process for two types of DESs solvent chosen was carried out. The selection of DES is made based on boiling point of DES whereby it must be higher than the temperature of devulcanisation which is about $180^{\circ} \mathrm{C}$. Based on thesis done by Ricky S. [39], it was determined that zinc chloride: urea and choline chloride: urea is the best selection for DES synthesis to be carried out.

In order to prepare DES, zinc chloride (salt) as the hydrogen bond acceptor and urea as the hydrogen bond donor was ordered and purchased under Sigma Aldrich Sdn. Bhd. Preparation of DES was made based on 1:4 and 2:7 molar ratio of $\mathrm{ZnCl}_{2}:$ Urea. By following the steps to prepare DES based on a research from [14], mass of $\mathrm{ZnCl}_{2}$ and urea were weighed accordingly and both compounds were added into a $100 \mathrm{ml}$ Schott bottle alongside a magnetic stirrer. The bottle was sealed with a parafilm to ensure minimum moisture content. This is to prevent the crystallization of DES from occurring. It was then placed onto a hot plate placed inside fume hood running at $300 \mathrm{rpm}$ and at $130-170^{\circ} \mathrm{C}$, in order to synthesize DESs solvent. The solvent is left approximately for 2-4 hours. It is considered successful if the solution obtained is clear and homogeneous. If it is not, then the process has to be repeated [13]. The reason for the DES samples to be conducted in a fume hood and sealing the cap with parafilm is to ensure no moisture goes into solvent. Table 1 depicts the molar ratio used for $\mathrm{ZnCl}_{2}$ :Urea solvent.

Table 1. Preparation of DES molar ratio

\begin{tabular}{|c|c|c|c|}
\hline Ammonium/Halide Salt & HBD & Molar Ratio & Freezing Point (K) \\
\hline $\mathrm{ZnCl}_{2}$ & Urea & $1: 4$ & 278.15 \\
\hline $\mathrm{ZnCl}_{2}$ & Urea & $2: 7$ & 275.15 \\
\hline
\end{tabular}

\subsection{Physicochemical properties of DES}

In order to determine whether the DES prepared is suited to be used as a devulcanising agent, Karl-Fischer Titration, Differential Scanning Calorimetric (DSC), Thermogravimetric Analysis (TGA) will be performed upon the prepared DES samples.

\subsubsection{Karl-fischer titration}

The moisture content of the prepared DES sample is done through KFT analysis whereby the moisture must not exceed $3 \mathrm{wt} \%$ as declared by C. Acids et al. [16]. To find out the accuracy and precision of the analysis instrument, $1.00 \mathrm{mg} / \mathrm{g}$ of Hydranal water standard was utilised whereby it was purchased and ordered from Sigma-Aldrich Malaysia.

\subsubsection{Differential scanning calorimetric analysis}

Freezing point of the synthesized DES is determined using the DSC available at Taylor's University School of Bioscience, where it will be carried out in nitrogen surrounding. Before conducting the experiment, the equipment is calibrated correctly to the standards values so that the accuracy of the readings obtained will be high. A portion of DES sample was extracted out and weighed between $5-10 \mathrm{mg}$ in a small pan. The small pan was then placed onto Perkin Elmer - DSC 8000 instrument analysis. The sample was first heated 
from $30^{\circ} \mathrm{C}$ to $60^{\circ} \mathrm{C}$ at a rate of $10 \mathrm{~K} / \mathrm{min}$, then cooled from $60^{\circ} \mathrm{C}$ to $-70^{\circ} \mathrm{C}$ at a rate of 5 $\mathrm{K} / \mathrm{min}$ and finally heated from $-70^{\circ} \mathrm{C}$ to $0^{\circ} \mathrm{C}$ at rate of $5 \mathrm{~K} / \mathrm{min}$. The suitable freezing point of the synthesized DES should lower than the constituent components and also, the preferred melting point of DES should be below $60^{\circ} \mathrm{C}$ [12].

\subsubsection{Thermogravimetric analysis}

The degradation temperature is determined through TGA analysis. The experiment is conducted at temperature of $180^{\circ} \mathrm{C}$. A portion of synthesized DES sample was extracted out and weighed between 5-10 mg into a small pan. The small pan was then placed onto Perkin Elmer - TGA 8000 instrument analysis allowing the analysis to be carried out from ambient temperature to $500^{\circ} \mathrm{C}$, with $10^{\circ} \mathrm{C}$ increment every minute under constant nitrogen purge gas of $40 \mathrm{ml} / \mathrm{min}$ environment [15]. The amount of liquid is measured as a temperature function.

\subsection{Rubber: DES sample preparation}

Once physiochemical properties of DES sample were measured and gave good results, devulcanisation of rubber samples were carried out next. Under this process, 4 variables were fixed which consist of sonication time, sonication frequency, DES molar ratios and heating time. Apart from that, 2 variables were varied which are heating temperature and rubber: DES mass ratio.

DES samples as shown in Table 1 were selected for the fact that they are aminocompound-based DESs which are suitable for desulphurisation process [28] and thus, it is considered to be the same condition for devulcanisation process. Rubber:DES mass ratio was varied at 1:20, 1:30 and 1:40 whereby the total mass of the rubber and DES should be equivalent to 50 grams. These ratios are specifically picked as to avoid sluggish mixture being formed which could render the devulcanisation process during ultrasonic treatment [3]. Rubber and DES were weighed accordingly to mass ratio and inserted inside the Schott bottle where it will be mixed thoroughly.

\subsection{Ultrasonic devulcanization \& heating treatment}

Once it is mixed thoroughly, the rubber sample mixtures were placed inside the ultrasonic water bath to undergo ultrasonic treatment at sonication time of 15 minutes at $37 \mathrm{kHz}$ [17]. During treatment, rubber: DES samples experienced and received the ultrasonic frequency wave in all possible directions. With the rubber and DES being exposed to ultrasonic wave, the cross-link bonds are overstressed which allows the sulphur-sulphur bonds as well crosslink bonds to become detached. Thus, penetration of DES is easier which leads to cleavage of cross-link bonds [3]. Through sonication, it is predicted that small fragments of the cross-link bond are broken. Therefore to further improve recovery, rubber: DES samples are subjected to heating treatment at 4 different temperatures for each sample after ultrasonic treatment.

Under this treatment, samples mixtures are transferred onto conical flask. It is then preceded by heating on hot plate in a fume hood environment at room temperature, $130^{\circ} \mathrm{C}$, $150^{\circ} \mathrm{C}$ and $180^{\circ} \mathrm{C}$ for 15 minutes. Heating temperatures was selected based on the flash point of rubber which is nearly $205^{\circ} \mathrm{C}$ [18-20]. Thus, heating temperature is recommended to be below the flash point temperature for safety aspects. A controlled sample was used to which it does not undergo ultrasonic water bath treatment and heating.

As soon as the heating process is completed, the rubber mixture sample was filtered out using a tea bag instead of a filter paper. This is due to the DES high viscosity which makes 
it very difficult for the rubber to be filtered out. The rubber mixture which was filtered was washed thoroughly with distilled water [18] to ensure there is no contamination of DES in the rubber mixture samples. Finally, the samples were placed inside the oven for approximately 24 hours at $70^{\circ} \mathrm{C}$ for it to dry.

Therefore, the total number of samples required for two different molar ratios, three different rubber:DES mass ratios as well four different heating temperatures is 30 . The following Table 2 and 3 depict the formulation and experimentation of the samples of various molar ratios.

Table 2. The formulation and experimentation of the sample 2:7 molar ratio

\begin{tabular}{|c|c|c|c|c|}
\hline $\begin{array}{c}\text { DES } \\
\text { molar ratio }\end{array}$ & Rubber:DES & $\begin{array}{l}\text { Sonication } \\
\text { time / min }\end{array}$ & $\begin{array}{c}\text { Heating } \\
\text { Temperature } /{ }^{\circ} \mathrm{C} \\
\end{array}$ & $\begin{array}{c}\text { Experimental } \\
\text { run }\end{array}$ \\
\hline \multirow{15}{*}{$2: 7$} & \multirow{5}{*}{$\begin{array}{c}1: 20 \\
(2.38 \text { gr }: 47.2 \text { gr })\end{array}$} & \multirow{4}{*}{15} & 30 & $1 \mathrm{~A}$ \\
\hline & & & 130 & $2 \mathrm{~A}$ \\
\hline & & & 150 & $3 \mathrm{~A}$ \\
\hline & & & 180 & $4 \mathrm{~A}$ \\
\hline & & \multicolumn{2}{|c|}{ Controlled sample } & $5 \mathrm{~A}$ \\
\hline & \multirow{5}{*}{$\begin{array}{c}1: 30 \\
(1.61 \mathrm{gr}: 48.39 \mathrm{gr})\end{array}$} & \multirow{4}{*}{15} & 30 & $6 \mathrm{~A}$ \\
\hline & & & 130 & $7 \mathrm{~A}$ \\
\hline & & & 150 & $8 \mathrm{~A}$ \\
\hline & & & 180 & $9 \mathrm{~A}$ \\
\hline & & \multicolumn{2}{|c|}{ Controlled sample } & $10 \mathrm{~A}$ \\
\hline & \multirow{5}{*}{$\begin{array}{c}1: 40 \\
(1.22 \mathrm{gr}: 48.78 \mathrm{gr})\end{array}$} & \multirow{4}{*}{15} & 30 & $11 \mathrm{~A}$ \\
\hline & & & 130 & $12 \mathrm{~A}$ \\
\hline & & & 150 & $13 \mathrm{~A}$ \\
\hline & & & 180 & $14 \mathrm{~A}$ \\
\hline & & \multicolumn{2}{|c|}{ Controlled sample } & $15 \mathrm{~A}$ \\
\hline
\end{tabular}

Table 3. The formulation and experimentation of the sample 1:4 molar ratio

\begin{tabular}{|c|c|c|c|c|}
\hline $\begin{array}{c}\text { DES } \\
\text { molar ratio }\end{array}$ & Rubber:DES & $\begin{array}{c}\text { Sonication } \\
\text { time } / \text { min }\end{array}$ & $\begin{array}{c}\text { Heating } \\
\text { Temperature } /{ }^{\circ} \mathbf{C}\end{array}$ & $\begin{array}{c}\text { Experimental } \\
\text { run }\end{array}$ \\
\hline $1: 4$ & $\begin{array}{c}1: 20 \\
(2.38 \mathrm{gr}: 47.2 \mathrm{gr})\end{array}$ & 15 & 30 & $1 \mathrm{~B}$ \\
\hline
\end{tabular}




\begin{tabular}{|c|c|c|c|}
\hline & & 130 & $2 \mathrm{~B}$ \\
\hline & & 150 & $3 \mathrm{~B}$ \\
\hline & & 180 & 4B \\
\hline & \multicolumn{2}{|c|}{ Controlled sample } & $5 \mathrm{~B}$ \\
\hline \multirow{5}{*}{$\begin{array}{c}1: 30 \\
(1.61 \mathrm{gr}: 48.39 \mathrm{gr})\end{array}$} & \multirow{4}{*}{15} & 30 & $6 \mathrm{~B}$ \\
\hline & & 130 & $7 \mathrm{~B}$ \\
\hline & & 150 & $8 \mathrm{~B}$ \\
\hline & & 180 & $9 \mathrm{~B}$ \\
\hline & \multicolumn{2}{|c|}{ Controlled sample } & $10 \mathrm{~B}$ \\
\hline \multirow{5}{*}{$\begin{array}{c}1: 40 \\
(1.22 \mathrm{gr}: 48.78 \mathrm{gr})\end{array}$} & \multirow{4}{*}{15} & 30 & $11 \mathrm{~B}$ \\
\hline & & 130 & $12 \mathrm{~B}$ \\
\hline & & 150 & $13 \mathrm{~B}$ \\
\hline & & 180 & 14B \\
\hline & \multicolumn{2}{|c|}{ Controlled sample } & $15 \mathrm{~B}$ \\
\hline
\end{tabular}

\subsection{Sample analysis}

Analysis on the rubber sample mixture can be carried out once the rubber is completely dry after being left in the oven for 24 hours. Fourier Transform Infrared Spectroscopy (FTIR) was performed on the rubber sample mixture since it revolves around the presence of the carbon-sulphur bonds.

\subsubsection{Fourier transform infrared spectroscopy}

The FTIR method used for this particular research study is the FTIR-ATR Spectrum 100. To make further confirmation, FTIR equipment allows the user to determine the specific bond that is broken down after devulcanisation process. This is done by analysing the spectrum generated from FTIR based on before and after data results of the rubber sample mixtures. In order to understand spectrum generated from FTIR, it is best to refer to journal by Garcia and co-workers et al. [13] so that the spectrum can be determined as to which compound it corresponds to specifically. Through this analysis, it is expected that there will be decrease in the intensity of the spectrum based on sulphur cross-link bonds during devulcanisation process. It is also expected that C-S and S-S bonds will decrease after the completion of devulcanisation process. 
Thermogravimetric analysis (TGA) analysis was carried out in with Shimadzu system form Japan. As reported by F. Endres et al. [21], it is heated within a certain temperature range, ranging from $20^{\circ} \mathrm{C}-600^{\circ} \mathrm{C}$, with an increment of $10^{\circ} \mathrm{C}$ per minute. The entire analysis was carried out in a nitrogen controlled environment. Through this analysis, degradation temperature of the rubber samples can be determined.

Experiment was carried out at temperature of $180^{\circ} \mathrm{C}$, in which small amount of DES is inserted into TGA tool. Analysis is carried out from ambient temperature to $500^{\circ} \mathrm{C}$, having an increment of $10^{\circ} \mathrm{C}$ per minute under a controlled nitrogen environment. Based on the TGA curve obtained from [35], a decreasing slope produced indicates there is a sudden drop in mass which indicates the degradation temperature of the rubber sample.

\section{Results and discussion}

The data obtained was analysed carefully and comparison was made based on previous research carried out on this topic. Results of the analysis will consist of DES characterization, FTIR and TGA results on the rubber sample mixtures.

\subsection{DES analysis of physicochemical properties}

In order to prepare DES, zinc chloride (salt) as the hydrogen bond acceptor and urea as the hydrogen bond donor was ordered and purchased Sigma Aldrich Sdn. Bhd. Preparation of DES was made based on 1:4 and 2:7 molar ratio of $\mathrm{ZnCl}_{2}$ : Urea. A homogeneous solution is obtained which has a very high viscosity at ambient temperature. Based on these, its physiochemical properties of the prepared DES samples such as moisture content, freezing point and degradation temperature is measured and determined.

The moisture content present inside the prepared DES samples must not exceed more than $3 \mathrm{wt} \%$ as it will affect and change its properties which could lead to crystallisation during devulcanisation process [22]. Thus 2 batches of different molar ratio of DES consisting of 1:4 and 2:7 were used to determine its respective moisture content. Based on Table 4, it can be seen that the moisture content for both the DES molar ratio does not exceed than the maximum allowable moisture content, thus they are suited to be used as a devulcanising agent.

Table 4. Moisture content of prepared DES sample

\begin{tabular}{|c|c|c|}
\hline DES molar ratio & Sample abbreviation & Moisture content (\%) \\
\hline $1: 4$ & DES 1 & 3.0000 \\
\hline $2: 7$ & DES 2 & 0.0717 \\
\hline
\end{tabular}

Freezing point is another important physiochemical property to be measured off from the prepared DES samples in order to show the liquidity range of the solvent and is ensured to be less than $60^{\circ} \mathrm{C}$ so that it can be applicable in industrial fields. By looking at the freezing point of DES obtained, its freezing point is below than its constituent component depicted in Table 5. This confirms a successful prepared synthesis of DES. Another confirmation of a successful synthesis of DES is the experimental freezing point obtained from the DSC analysis is compared with the literature value from $[13,21]$, whereby it show a small percentage error between the readings obtained.

Table 5. Moisture content of prepared DES sample 


\begin{tabular}{|c|c|c|c|}
\hline \multirow{2}{*}{ Solvent } & \multicolumn{2}{|c|}{ Freezing point (K) } & \multirow{2}{*}{ Percentage error (\%) } \\
\cline { 2 - 3 } & Literature & Experimental & \\
\hline DES 1 & 278.15 & 288.15 & 3.47 \\
\hline DES 2 & 275.15 & 278.81 & 1.31 \\
\hline
\end{tabular}

Degradation temperature of the prepared DES sample is an important requirement to be known so that DES prepared earlier does not degrade at $180^{\circ} \mathrm{C}$ which is operating temperature of devulcanisation. The measurement is carried out accordingly as mentioned in sub-section 2.2.3. The following two figures below depicts the weight loss of $\mathrm{ZnCl}_{2}$ :Urea for two different molar ratio vs. temperature.

Based on the TGA curve reported by Seghar et al. [15], a decreasing slope produced indicates there is a sudden drop in mass. This point at which it has a sudden drop is the degradation temperature of the DES. Referring to Figure 1a and 1b, it can be seen that the degradation temperature was found to be at $187.35^{\circ} \mathrm{C}$ and $324.36^{\circ} \mathrm{C}$ respectively for $2: 7$ and 1:4 molar ratio. The values obtained clearly states that devulcanisation temperature must not be allowed to reach to the degradation temperature to avoid the DES degradation. Therefore, the prepared DES samples are suited to be used for this particular devulcanisation research study. In addition to that, the operating temperature of the devulcanisation used is below the DES degradation temperature, making it a suitable operating temperature for devulcanisation process.

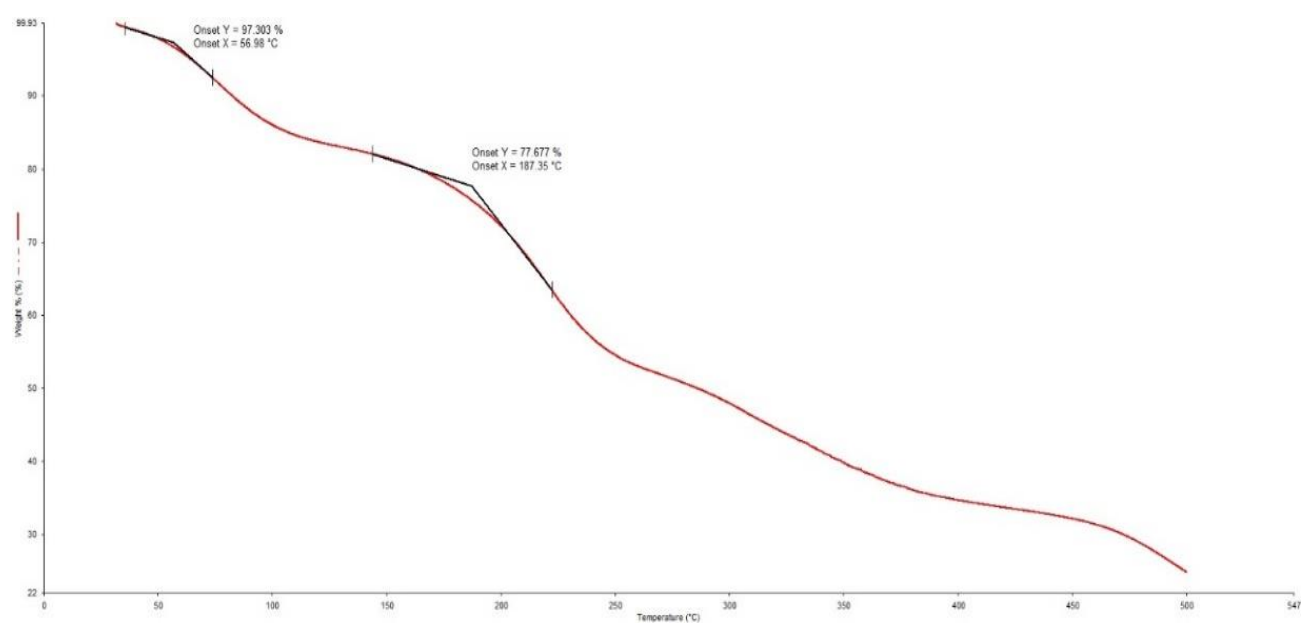

(a) 


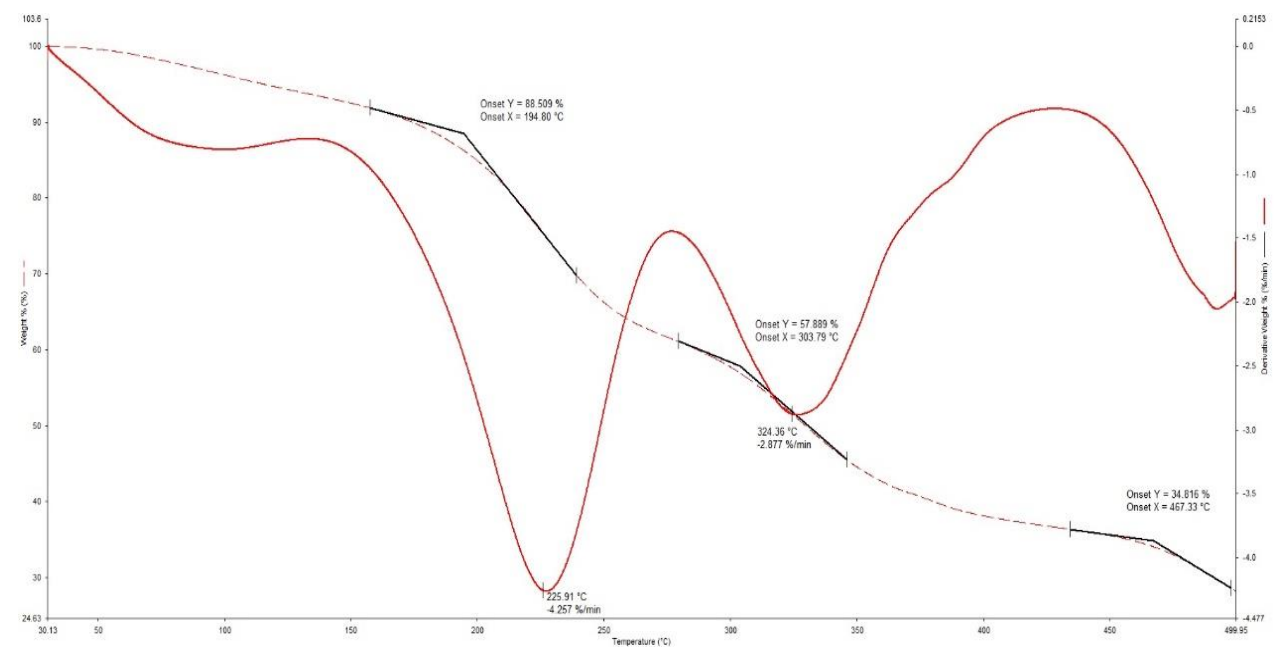

(b)

Fig. 1. TGA analysis for DES molar ratio of (a) 2:7 and (b) $1: 4$

\subsection{Analysis of devulcanized rubber}

Analysis is performed on the devulcanised rubber mixture samples on its structural bonds and temperature degradation using FTIR and TGA respectively. Then the analysis is followed by composition, morphological structure and gel content analysis.

\subsubsection{Fourier transform infrared spectroscopy analysis}

FTIR graph for the first three samples treated with DES 1 is shown in Figure 2a, b and c.

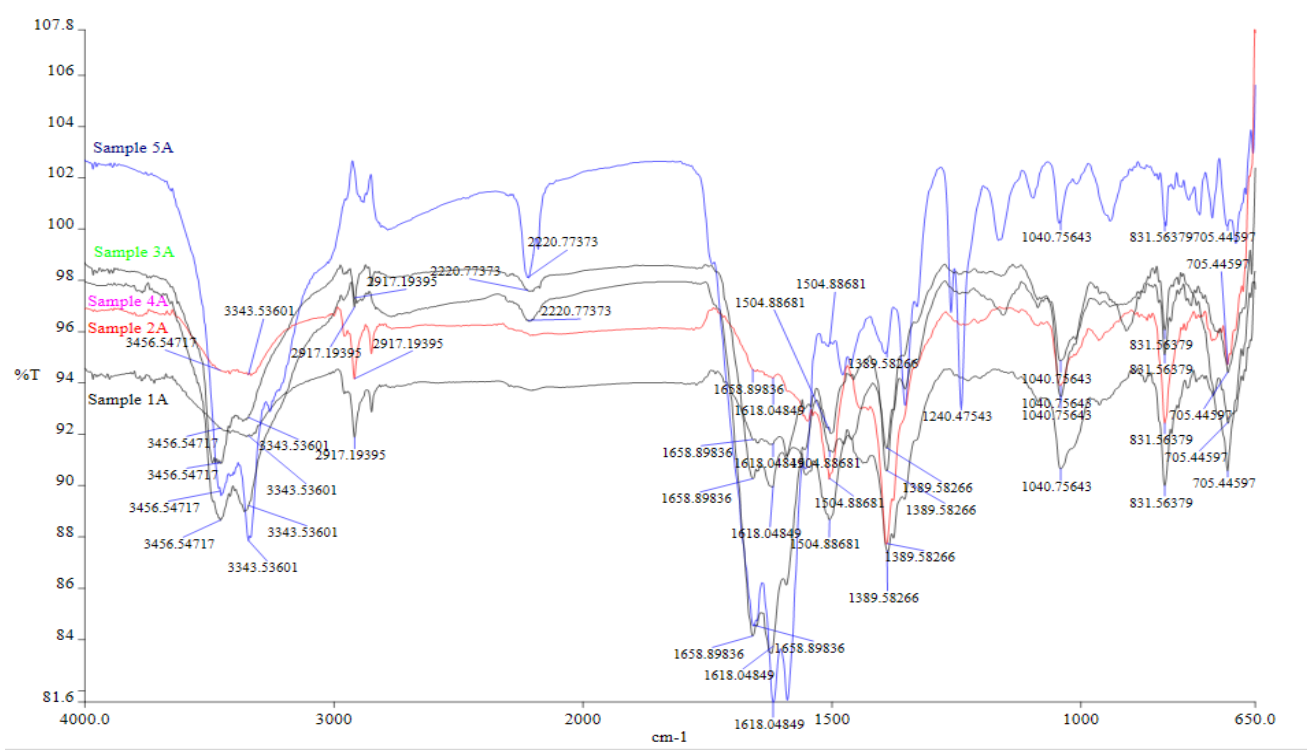

(a) 


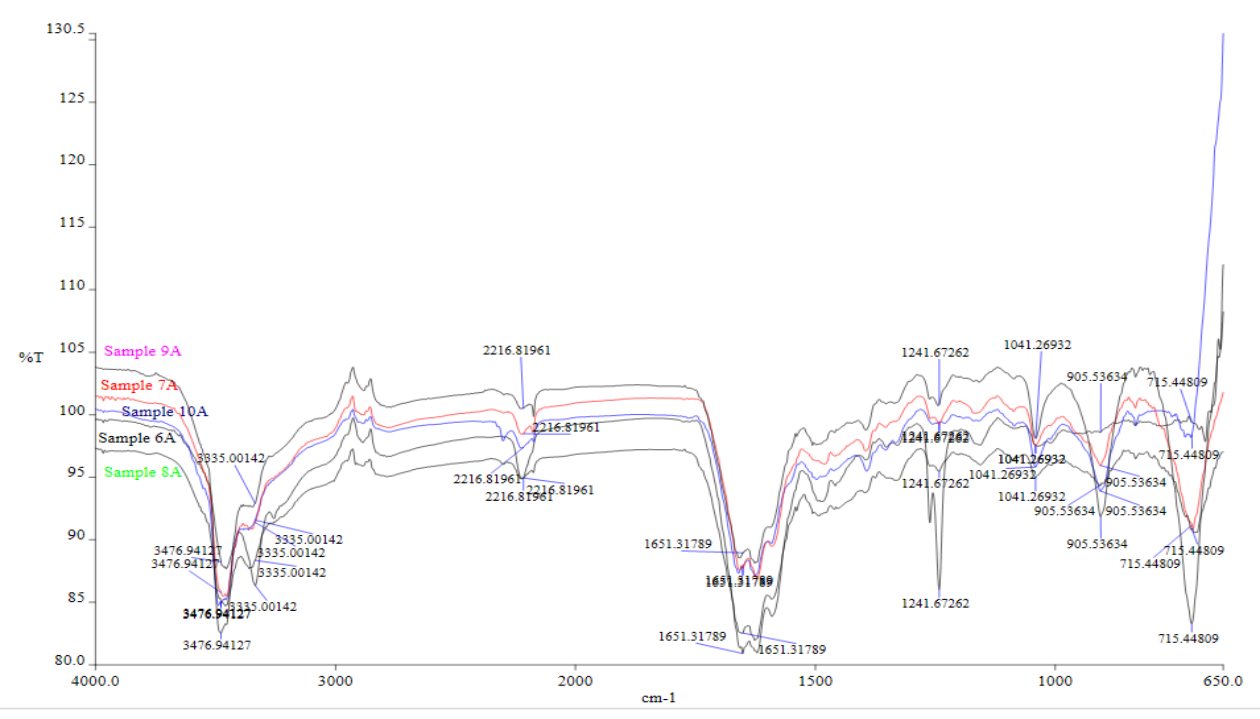

(b)

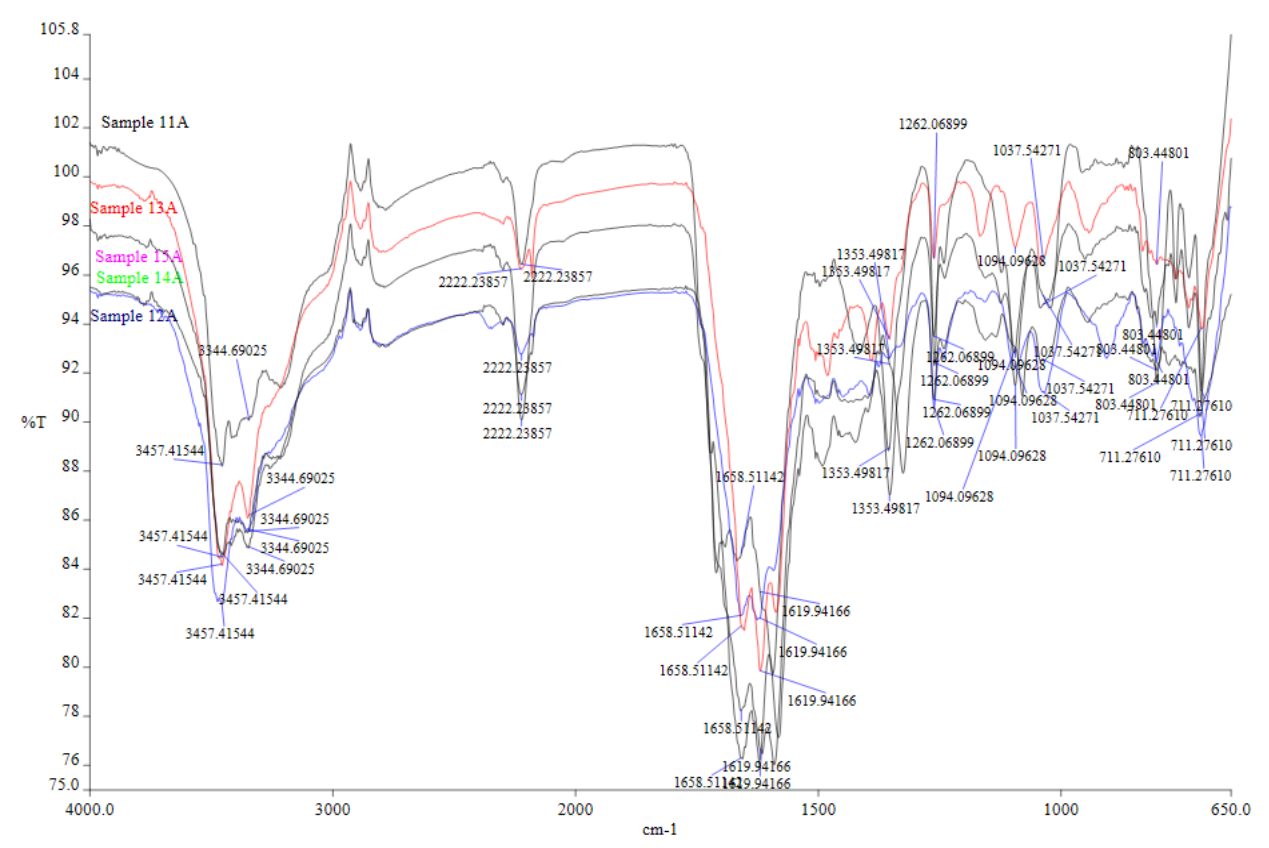

(c)

Fig. 2. FTIR analysis for rubber:DES mass ratio at (a) 1:20, (b) 1:30 and (c) 1:40

Referring to Figure 2a, it can be seen that above $3550 \mathrm{~cm}^{-1}$, there is an appearance of a broad peak especially for Sample 1A and 2A, which indicates that the presence of $\mathrm{O}-\mathrm{H}$ group. This also indicates water presence which might still remain in the sample. Presence of water is due to the fact the rubber sample mixture was washed previously with distilled water so droplets of water might still be present. Thus, it can be said that there is a low amount of rubber degradation happening. 
In Figure $2 \mathrm{a}$ and $2 \mathrm{c}$, wavelength for $-\mathrm{CH}_{3}$ functional group makes an appearance in the region of $1389.58266 \mathrm{~cm}^{-1}$ and $1353.49817 \mathrm{~cm}^{-1}$ respectively for all of the samples. However, for rubber: DES mass ratio at 1:20 in Figure $2 \mathrm{~b}$, there was no presence of $-\mathrm{CH}_{3}$ functional group, in other words there is no structural change. Aside from that, functional group of -CH- appears at the region of $2917.19395 \mathrm{~cm}^{-1}$ for mass ratio at 1:20 as shown in Figure 2a. Despite that, there was no peak appearance of the functional group $-\mathrm{CH}$ - for mass ratio at 1:30 and 1:40.

-S-S- functional group or bond was analysed at wavelength between $700-550 \mathrm{~cm}^{-1}$ and it can be identified that sample 1A, 2A, 3A, 4A, 6A, 7A, 8A, 9A, 11 A, 12A, 13A, and 14A have a peak appearance indicating bond reformation is occurring. On the other hand, sample 5A, 10A and 15A does not have any peak appearance since it is a controlled sample, therefore there is no reformation occurring. Another bond that was analysed is the $-\mathrm{C}-\mathrm{S}$ - bond for which it falls in the wavelength region of $700-520 \mathrm{~cm}^{-1}$. Since there is still peak appearance in Figure 2a, b and c for all the samples, hence it can be said that bonds have not been broken down. Thus, it can be concluded that ultrasonic treatment was unable to break the bond which has higher bond energy than -S-S- bond.

Another analysis was made based on bonds through FTIR analysis as shown in Figure $3 \mathrm{a}, \mathrm{b}$ and $\mathrm{c}$ for devulcanisation process of $\mathrm{ZnCl}_{2}$ :Urea for $2: 7$ molar ratio at different mass ratio.

Based on FTIR curve plotted from Figure $3 a, 3 b$ and $3 c$, it can be analysed that for mass ratio of 1:30, there is disappearance of -S-S- peak whereas for mass ratio of 1:20 and 1:40, there is an appearance of -S-S- peak. Carbon-sulphur bond for this particular treatment is also not broken down since it has a low supply of energy, resulting in zero cleavage of sulphur cross-link bond. From Figure 3b, it also can be seen that there is a disappearance of -S-S- peak for sample $8 \mathrm{~B}$. This occurs because of the uneven dispersion particles of rubber or rubber mixture sample composition during devulcanisation process.

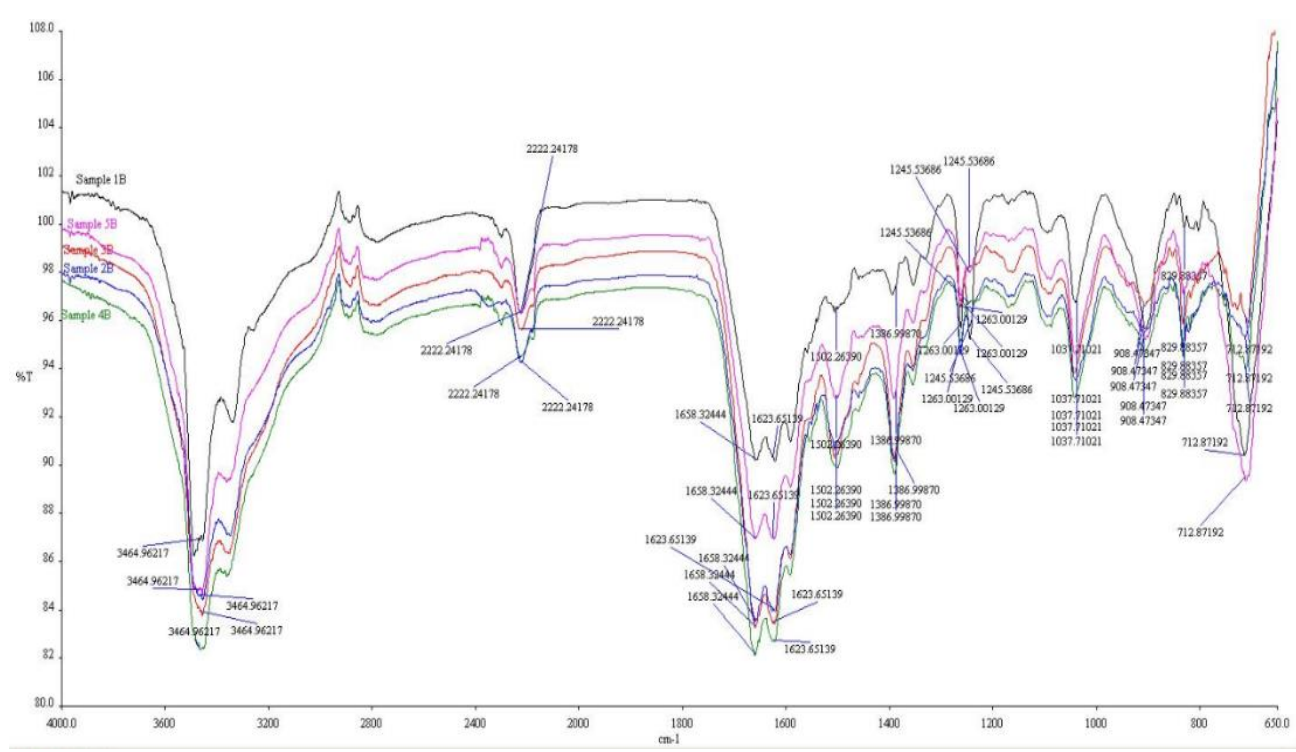

(a) 


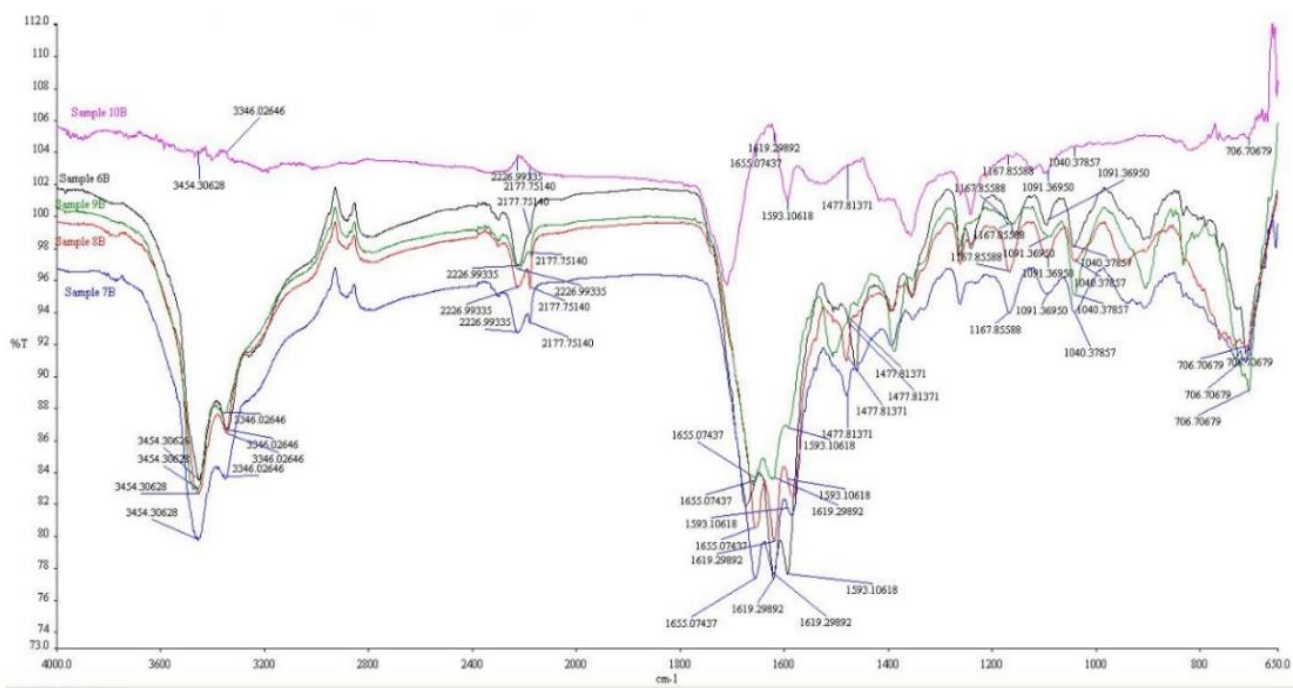

(b)

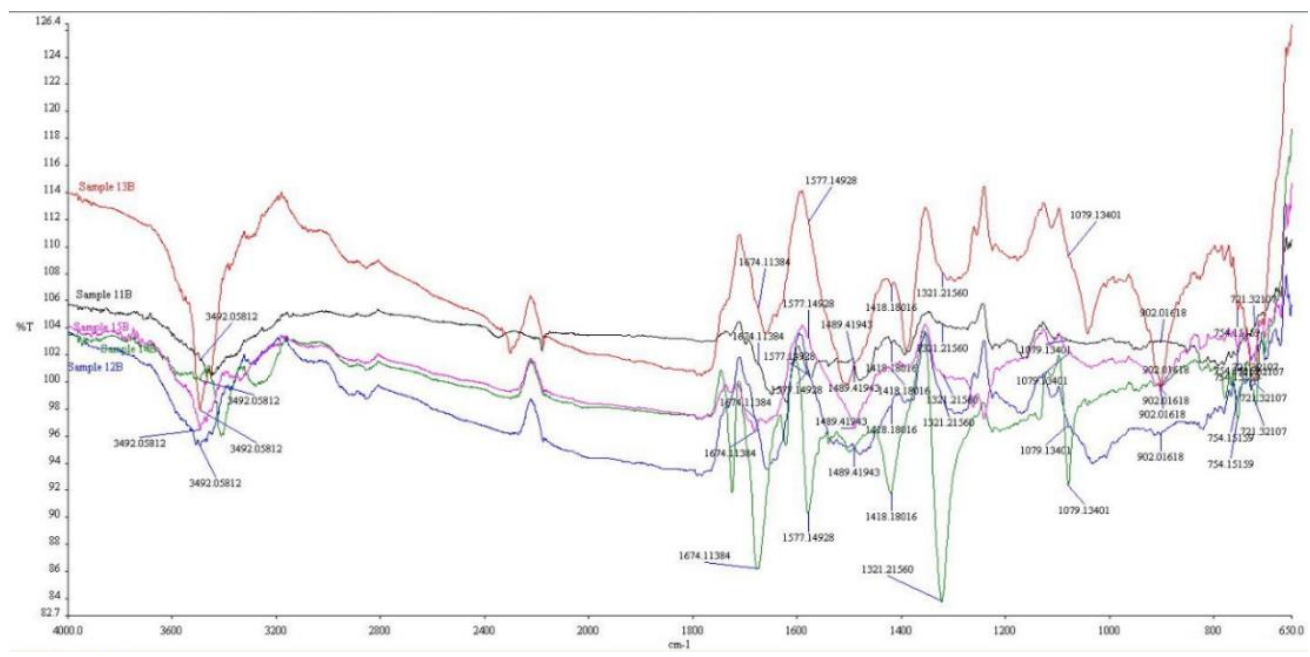

(c)

Fig. 3. FTIR analysis for rubber:DES mass ratio (a) 1:20, (b) 1:30 and (c) 1:40

From Figure 2 and 3, it can be said that wavelength range which are 1300 and $3500 \mathrm{~cm}$ 1 , there is no appearance of a peak other than broad peak which is apparent at above 3000 $\mathrm{cm}-1$ wavelength range. Therefore, this shows there is still presence of water inside the rubber mixture sample. Thus, it can deduced that there is low amount of degradation rubber which contains the -O-H group.

All in all, various conclusion can be deducted that through FTIR analysis. It was determined through FTIR analysis that -S-S- or sulphur-sulphur bond is the only bond which is leaved during devulcanisation process which proves a successful devulcanisation process at an optimum heating temperature of $130^{\circ} \mathrm{C}$. Other bonds are not broken or cleaved as there was insufficient energy to cleave them. Hence, the main carbon chain is still maintained even after devulcanisation process was carried out which further proves that devuclanised rubber has excellent physical properties. 


\subsubsection{Thermogravimetric analysis}

Based on the TGA curve obtained from S. Seghar et al. [15], a decreasing slope produced indicates there is a sudden drop in mass. This point at which it has a sudden drop is the degradation temperature of the rubber samples mixture. Referring to Figure 4, it can be seen that the degradation temperature for sample $1 \mathrm{~A}, 2 \mathrm{~A}, 3 \mathrm{~A}, 4 \mathrm{~A}, 5 \mathrm{~A}$ was found to be at $288.0^{\circ} \mathrm{C}, 298.29^{\circ} \mathrm{C}, 325.23^{\circ} \mathrm{C}, 332.95^{\circ} \mathrm{C}$ and $112.59^{\circ} \mathrm{C}$ respectively. Degradation temperature for sample $4 \mathrm{~A}$ is highest among the rest of the samples. However degradation for sample $1 \mathrm{~A}$ is comparably much smaller than the rest.

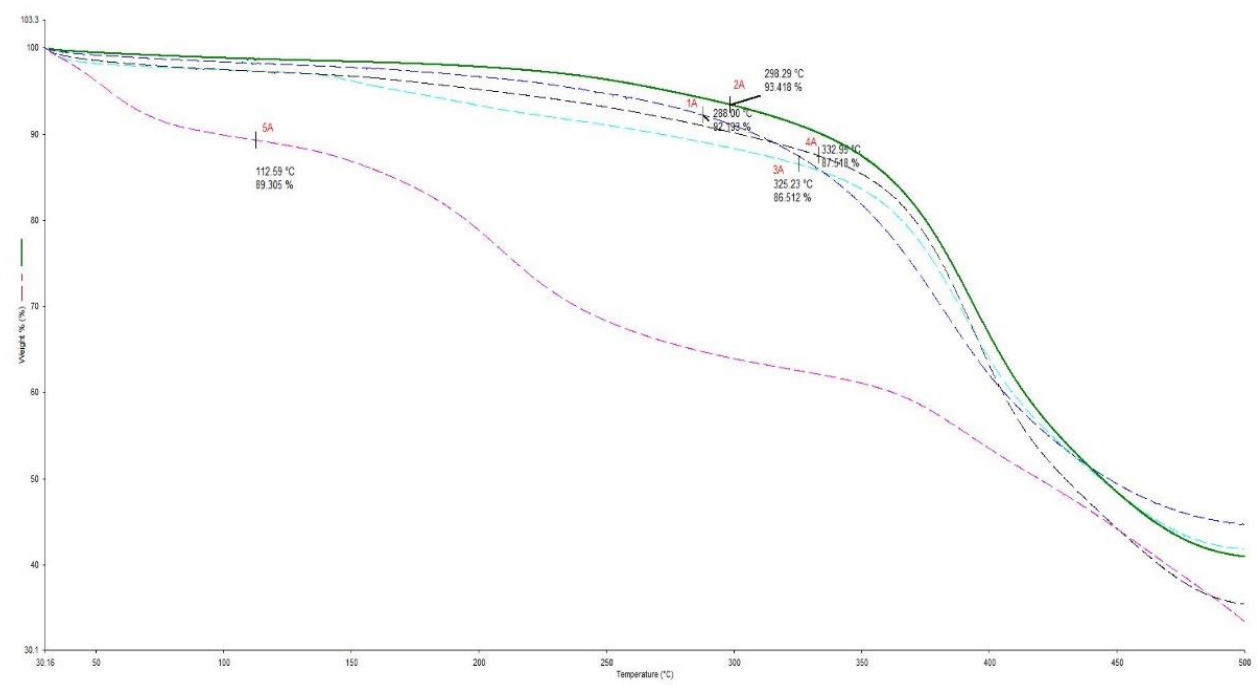

Fig. 4. TGA analysis for samples $1 \mathrm{~A}$ to $5 \mathrm{~A}$ at 1:20 mass ratio

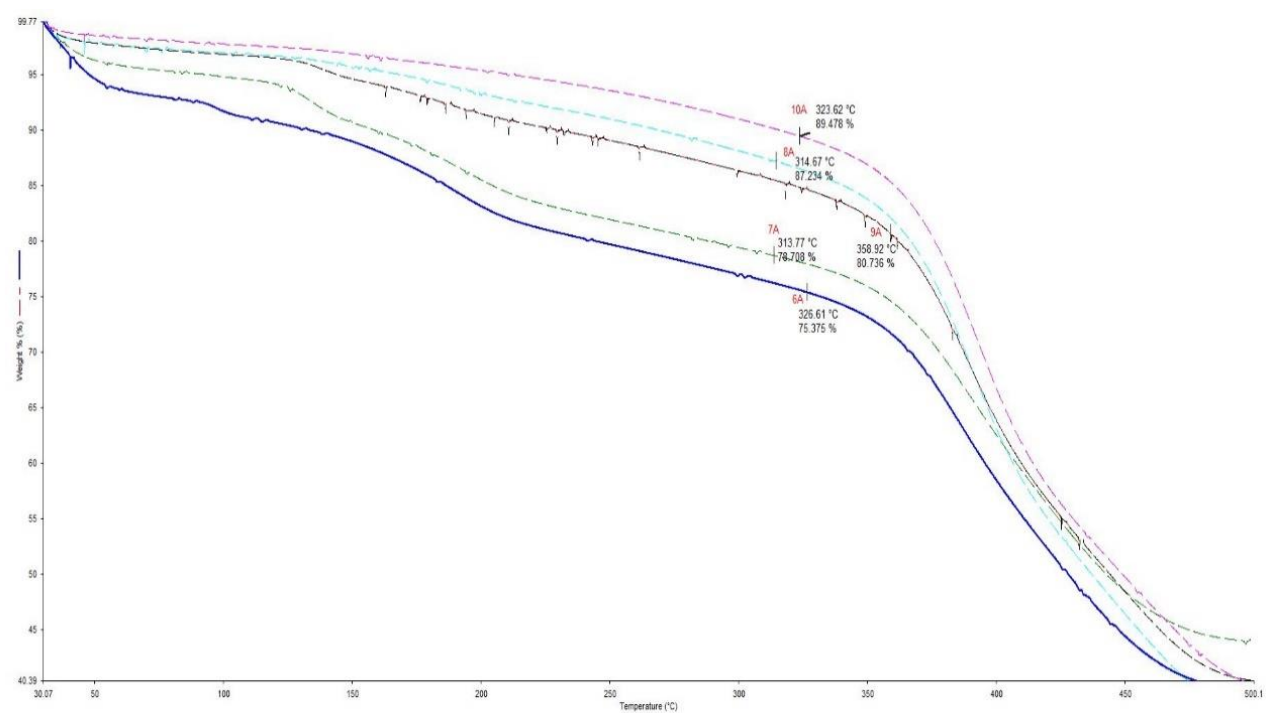

Fig. 5. TGA analysis for samples $6 \mathrm{~A}$ to $10 \mathrm{~A}$ at 1:30 mass ratio 
Next, with respect to Figure 5, it can be seen that the degradation temperature for sample $6 \mathrm{~A}, 7 \mathrm{~A}, 8 \mathrm{~A}, 9 \mathrm{~A}, 10 \mathrm{~A}$ was found to be at $326.61^{\circ} \mathrm{C}, 313.77^{\circ} \mathrm{C}, 314.67^{\circ} \mathrm{C}, 358.92^{\circ} \mathrm{C}$ and $323.62^{\circ} \mathrm{C}$ respectively. Degradation temperature for sample $9 \mathrm{~A}$ is highest among the rest of the samples. However degradation for sample 7A is comparably much smaller than the rest. Similarly observation from Figure 6 gives the fact that the degradation temperature for sample $11 \mathrm{~A}, 12 \mathrm{~A}, 13 \mathrm{~A}, 14 \mathrm{~A}, 15 \mathrm{~A}$ are $313.45^{\circ} \mathrm{C}, 302.51^{\circ} \mathrm{C}, 314.95^{\circ} \mathrm{C}, 312.88^{\circ} \mathrm{C}$ and $350.30^{\circ} \mathrm{C}$ respectively whereby the highest degradation temperature is possessed by sample $15 \mathrm{~A}$ while the lowest is on sample $12 \mathrm{~A}$.

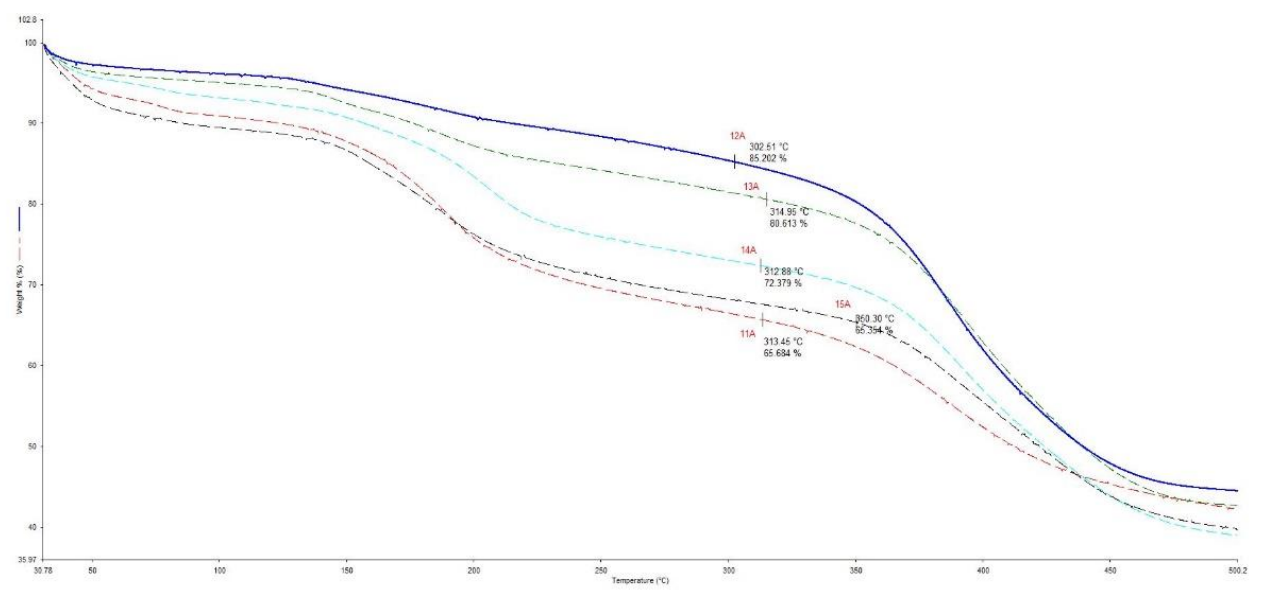

Fig. 6. TGA analysis for samples $11 \mathrm{~A}$ to $15 \mathrm{~A}$ at $1: 40$ mass ratio

With respect to Figure 4-6 for treatment of rubber with $\mathrm{ZnCl}_{2}:$ Urea at 2:7, the trend that can be observed is that the controlled sample possesses the highest degradation temperature as $-\mathrm{S}$-S- and/or $-\mathrm{C}-\mathrm{S}$ - bonds still intact into the rubber. However, as more $-\mathrm{S}-\mathrm{S}$ - and/or $-\mathrm{C}$ $\mathrm{S}$ - extracted, degradation temperature also reduces as expected. Thereby, the most optimum devulcanization heating temperature at fixed sonication time and frequency as well as heating time of 15 minutes for treatment with $\mathrm{ZnCl}_{2}: \mathrm{Urea}(2: 7)$ is $130^{\circ} \mathrm{C}$.

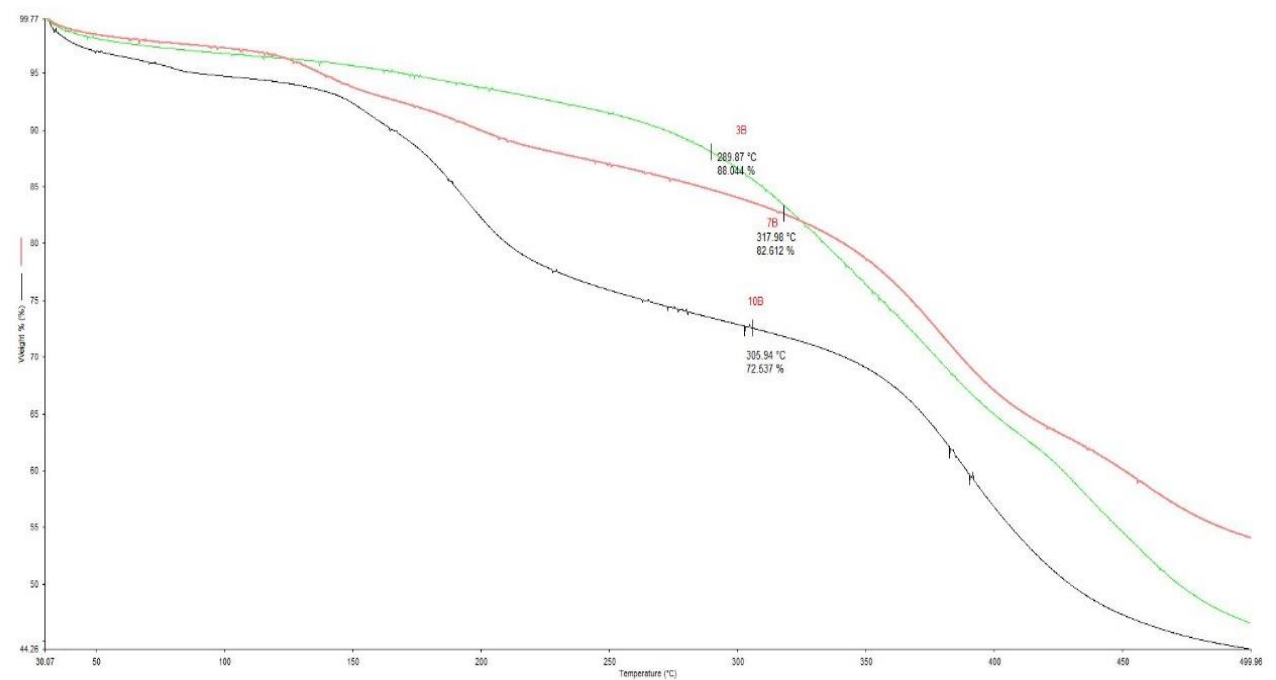

Fig. 7. TGA analysis for samples 3B, 7B and 10B 
Continue on to analysis of treatment with $\mathrm{ZnCl}$ :Urea at 1:4, Figure 7 that shows the degradation temperature of sample $3 \mathrm{~B}, 7 \mathrm{~B}$ and $10 \mathrm{~B}$ which are at $289.97^{\circ} \mathrm{C}, 317.98^{\circ} \mathrm{C}$, and $305.94^{\circ} \mathrm{C}$ respectively whereby it was found that sample $7 \mathrm{~B}$ has the highest degradation temperature while sample $3 \mathrm{~B}$ is the lowest with respect to controlled sample 10B.

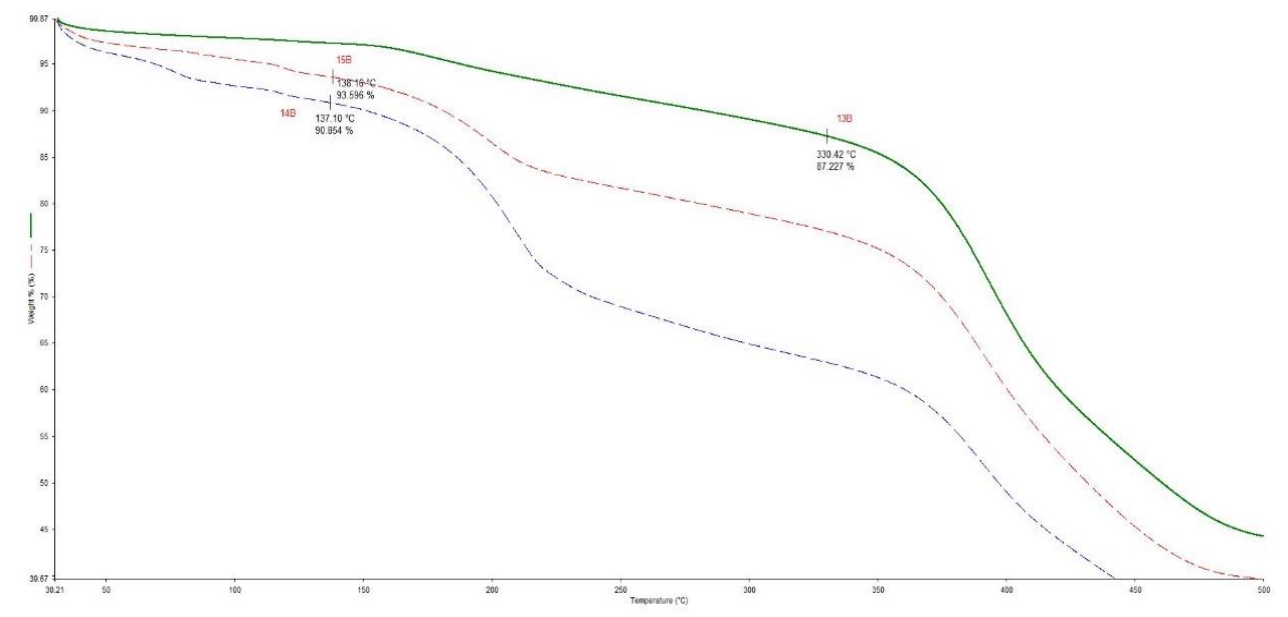

Fig. 8. TGA analysis for samples 13B, 14B and 15B

Moving on to Figure 8, it can be seen that the degradation temperature for sample 13B, $14 \mathrm{~B}$, and $15 \mathrm{~B}$ was found to be at $330.42^{\circ} \mathrm{C}, 137.10^{\circ} \mathrm{C}$, and $138.16^{\circ} \mathrm{C}$ respectively. In a similar manner, degradation temperature for sample 13B is the highest among the rest of the samples, while 14B is the lowest in comparison with controlled sample 15B.

Conclusively for treatment with $\mathrm{ZnCl}_{2}$ :Urea at 1:4 molar ratio, it is found that the degree of devulcanization increases as the heating temperature increases which indicated by lower degradation temperature with the minimum temperature setting of $150^{\circ} \mathrm{C}$.

\subsubsection{EDX analysis}

Results acquired for composition of rubber sample from before and after devulcanisation process through EDX analysis is depicted in Figure 9 for $\mathrm{ZnCl}_{2}$ :Urea for $2: 7$ molar ratio, whereby the graph is plotted in terms of sulphur removal percentage against heating temperature.

Referring to Figure 9, it can be observed that, for mass ratio of 1:30 and 1:40, the sample is having an increase in devulcanisation process efficiency as the temperature increases from $150^{\circ} \mathrm{C}$ to $180^{\circ} \mathrm{C}$. Thus, this shows that cross-link network is being broken and soluble fraction is increasing. In fact, at temperature $130^{\circ} \mathrm{C}$, it has the highest percentage removal of sulphur which indicates that devulcanisation efficiency is particularly high at that temperature. Reduction in devulcanisation efficiency can be seen for rubber sample under mass ratio of $1: 20$ as the temperature increases from $150^{\circ} \mathrm{C}$ to $180^{\circ} \mathrm{C}$. This is due to the fact that bond reformation is occurring during heating treatment as the sulphur cross-link bonds are being reformed again. 


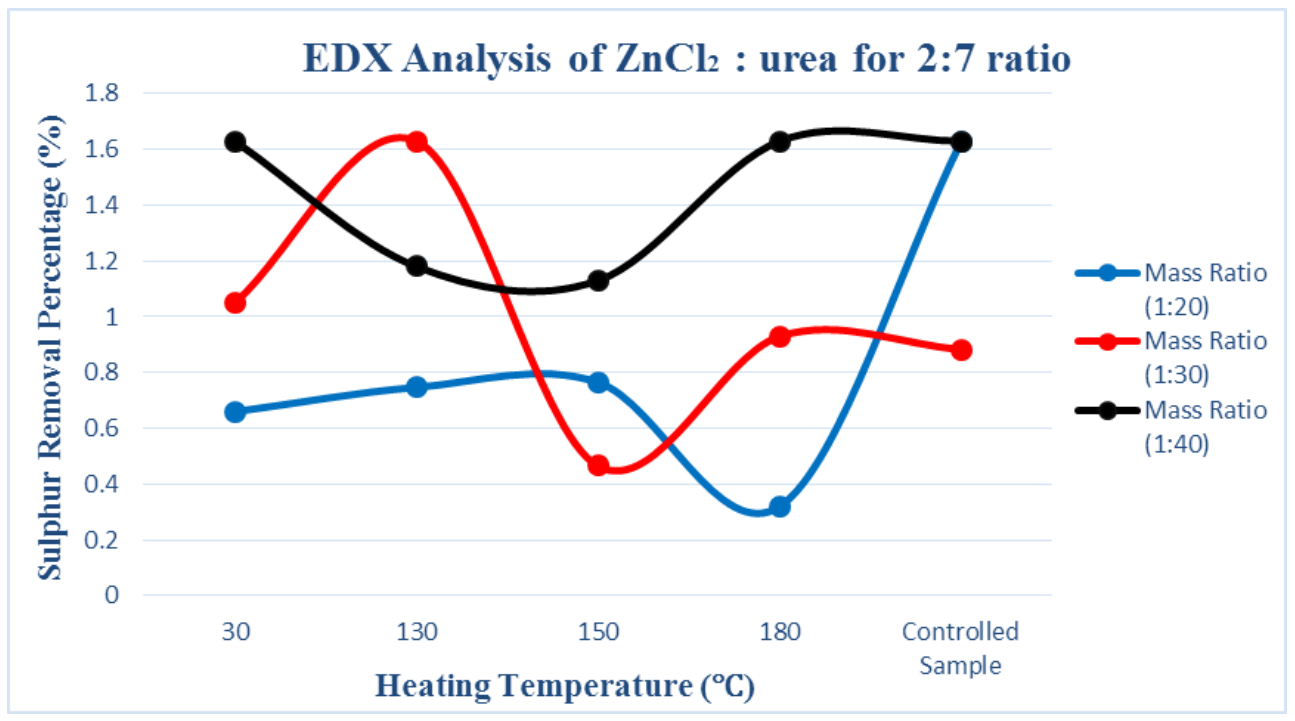

Fig. 9. EDX analysis for $\mathrm{ZnCl}_{2}:$ Urea for $2: 7$ molar ratio

Based on the results acquired, it can be deduced that during devulcanisation, bond reformation and bond cleaving of the sulphur-sulphur bond or carbon-sulphur bond can simultaneously occur as proven by [7]. Therefore, heating temperature is key process parameter in order to have a successful devulcanisation process. Hence, for this case, the optimum heating temperature is $130^{\circ} \mathrm{C}$ for rubber samples at $1: 20$ and $1: 30$ mass ratio at maximum removal of sulphur content

With bond reformation happening, it can explained that as bonds are cleaved or broken down, sulphur still remains inside the rubber sample together with free electrons which are detached from the -C-S- bond. Thus, this leads to carbon active sites formation which allows the sulphur to reform the sulphur cross-link bonds again by utilising those free electrons released. At a temperature of $130^{\circ} \mathrm{C}$, rubber samples will have the highest removal of sulphur content if the heating treatment is stopped at moment. Despite that, temperature above $130^{\circ} \mathrm{C}$ will result in decrease in devulcanisation efficiency and bond reformation, allowing removed sulphur to reform back again with carbon backbone by utilising those free electrons. Therefore, it is important to stop at the optimum temperature in order to avoid bond reforming from occurring and to also ensure the maximum removal of sulphur content from the rubber sample mixture.

Based on Figure 9, in terms of mass ratio, it can be shown that using higher amount of DES will result in higher devulcanisation efficiency. This means that degree of cleavage on the cross-link bonds will be greater. This is because DES capacity is higher allowing the bond to break more easily. Nonetheless, it is an inconclusive hypothesis due to the uneven trend displayed for the rubber sample at 1:30 mass ratio.

The cause of such uneven trend displayed by the rubber sample might be due to nonhomogenous of rubber sample mixture. This is because the sample mixture might not been completely well mixed, thus leading to such trend as shown in Figure 9. Another cause to it might be due to the rubber not completely mixed with DES as this DES has a very high viscosity, making it hard to mix both components. This will eventually leads in forming a two layered mixture due to density difference whereby devulcanisation process under ultrasonic treatment will be affected entirely. 


\subsubsection{FESEM Analysis}

For this analysis, study on the morphology of rubber before and after devulcanisation was carried out using FESEM analysis. The findings of the results were discussed in detailed in the following section below.

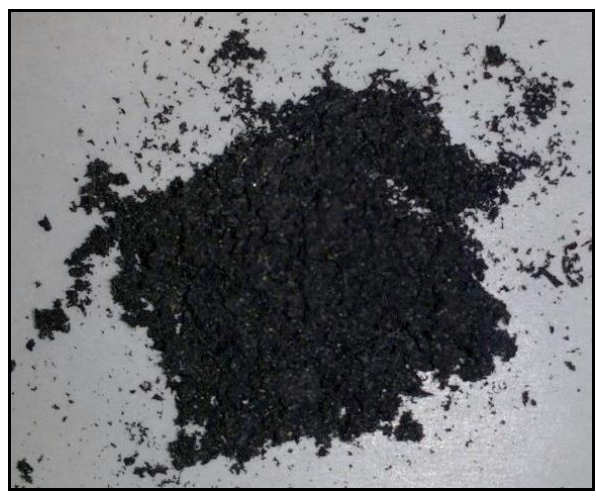

(a)

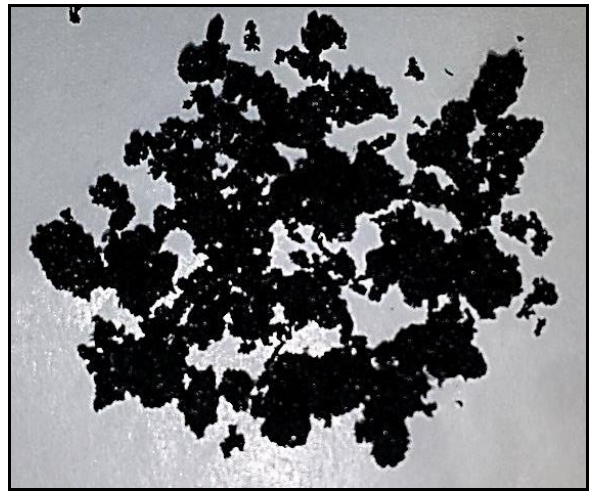

(b)

Fig. 10. (a) Vulcanised rubber sample and (b) Devulcanised rubber sample

Properties of devulcanised rubber as shown in Figure 15 consist of soft, sticky in nature and feels rougher compared to unvulcanised rubber. Displaying these kind properties indicates that devulcanisation process was a success. FESEM analyses are carried out for each rubber sample through the use of different solvent agent. To make a confirmation on whether rubber has been vulcanised efficiently, it depends entirely on the gaps presence and smooth surface of the rubber morphology sample. In Figure 16, it shows the FESEM analysis on devulcanised rubber for all of the samples based on $\mathrm{ZnCl}_{2}$ :Urea for 2:7 molar ratio.

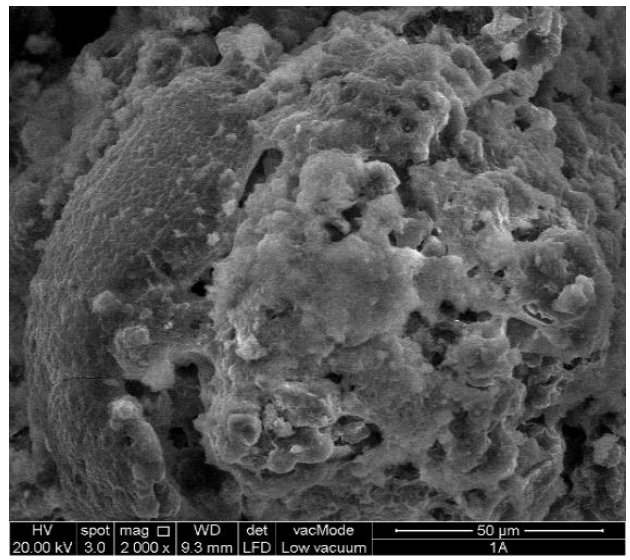

(a)

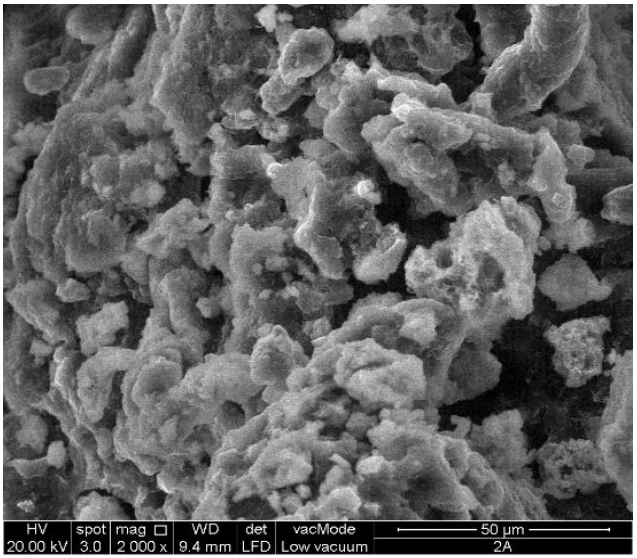

(b) 


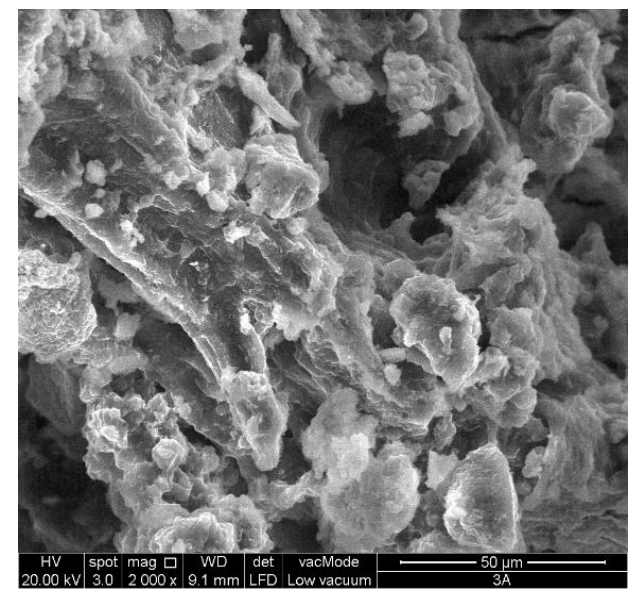

(c)

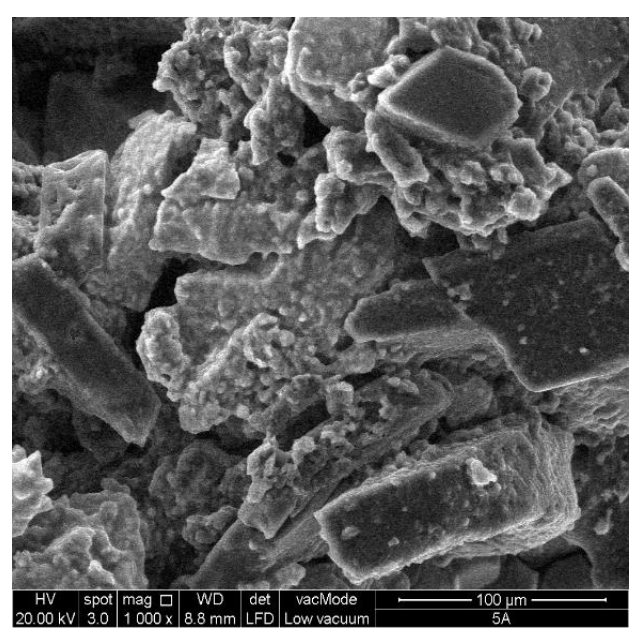

(e)

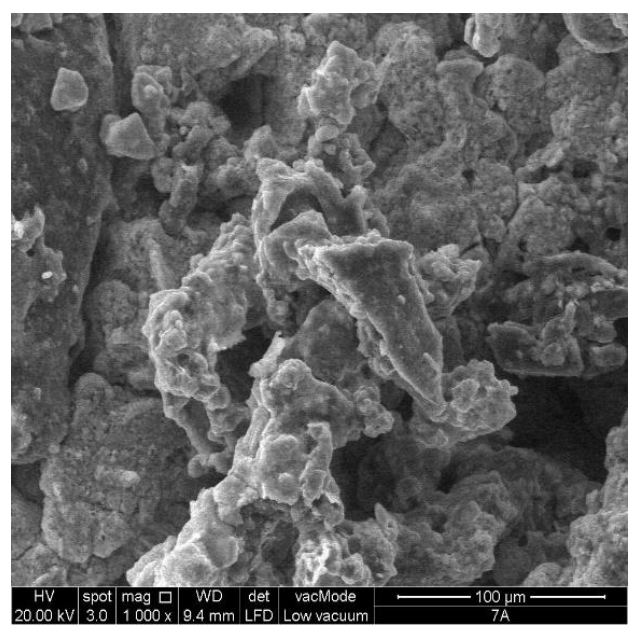

(g)

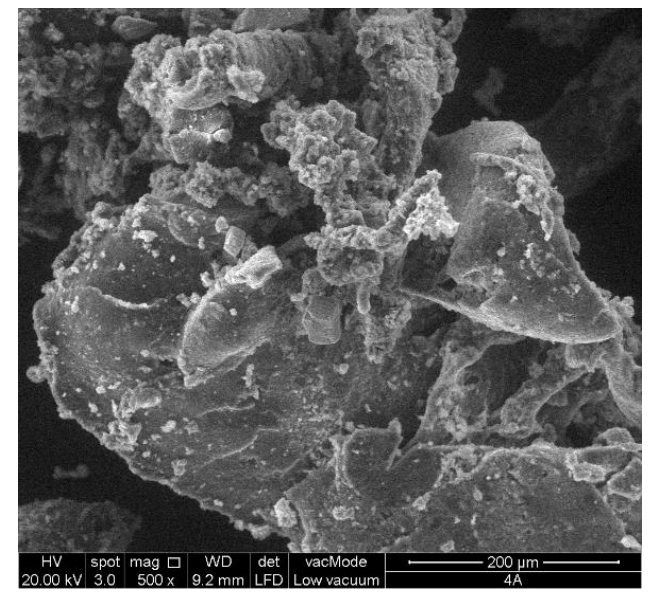

(d)

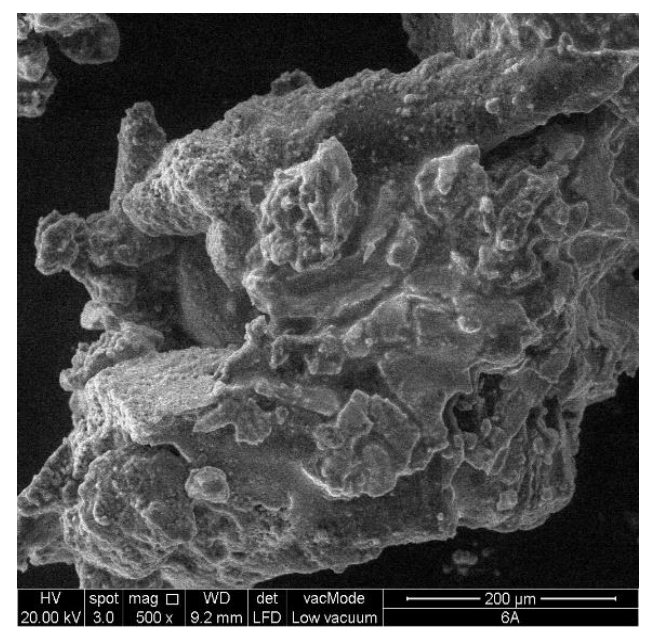

(f)

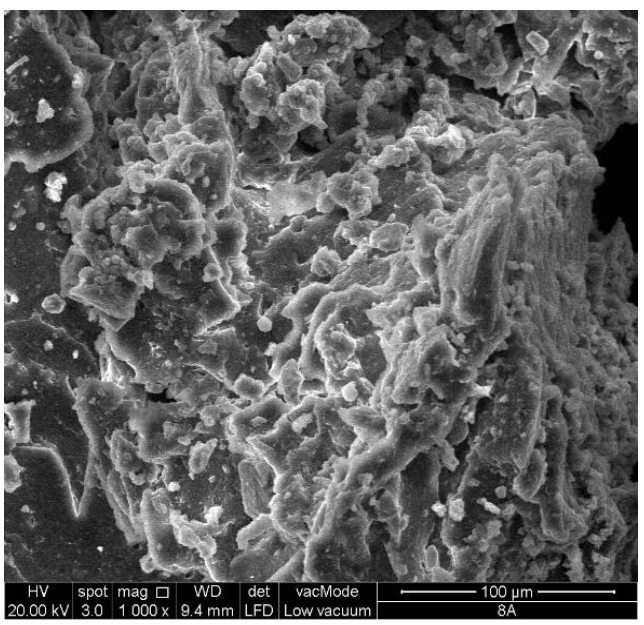

(h) 


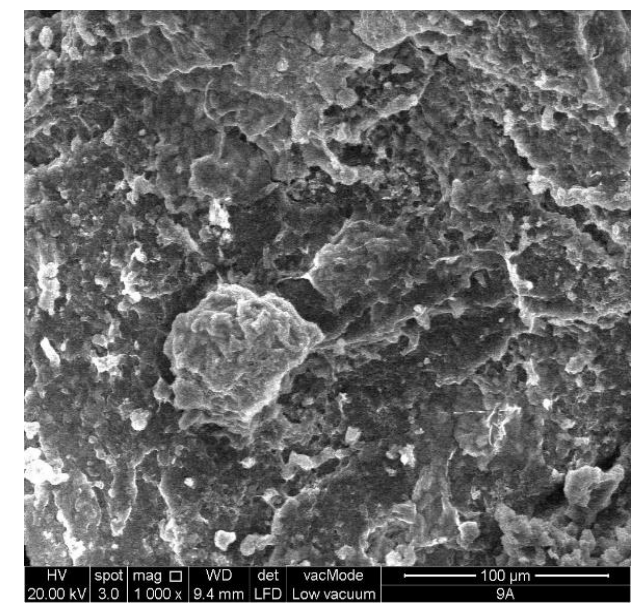

(i)

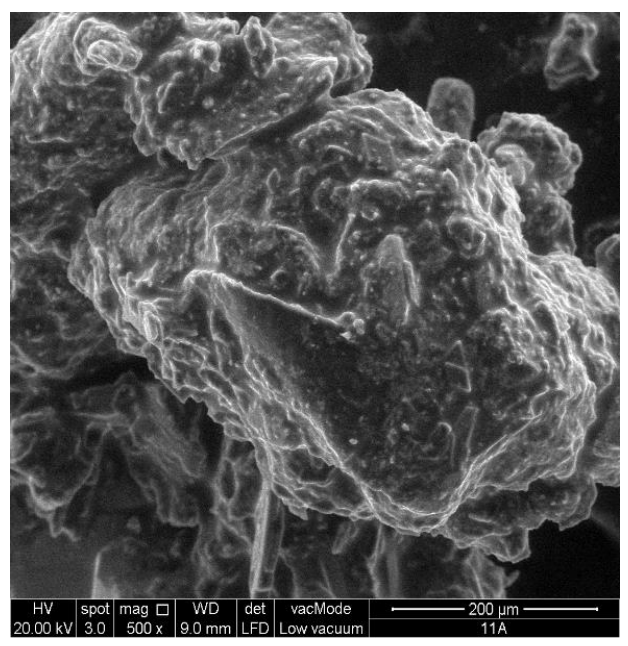

(k)

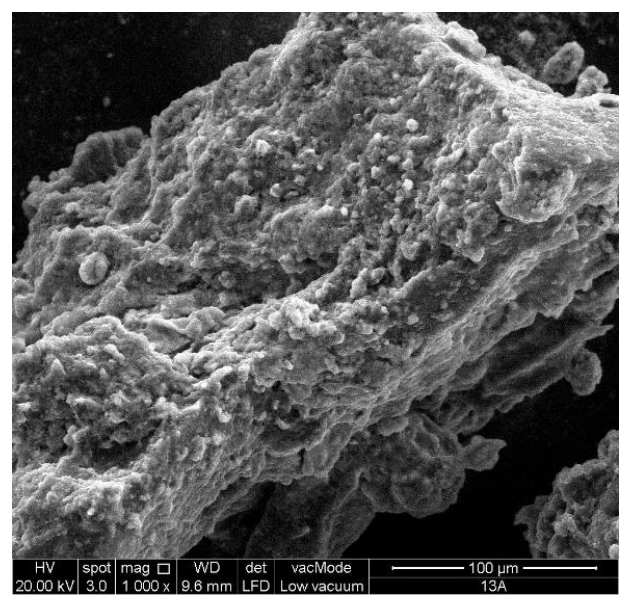

(m)

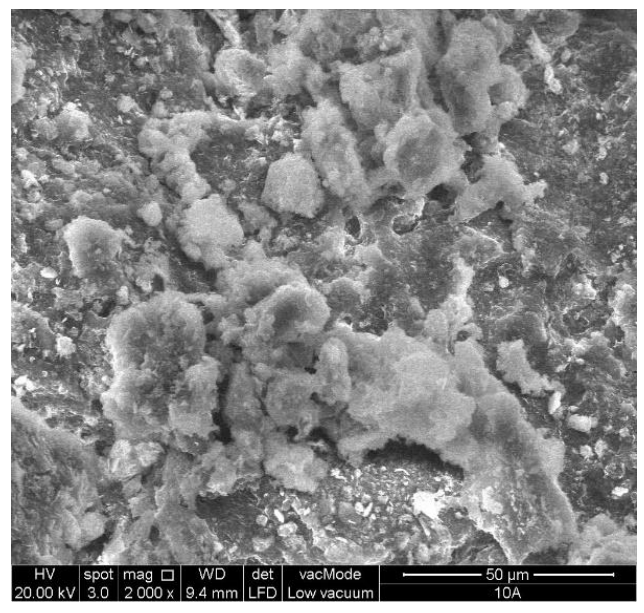

(j)

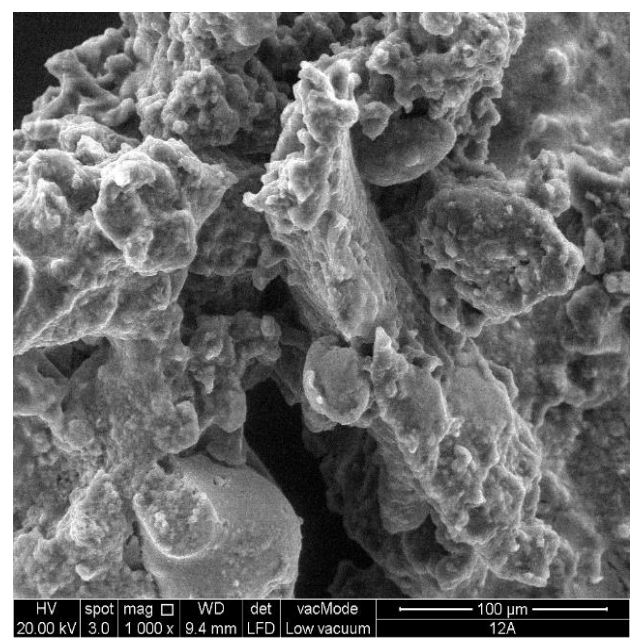

(1)

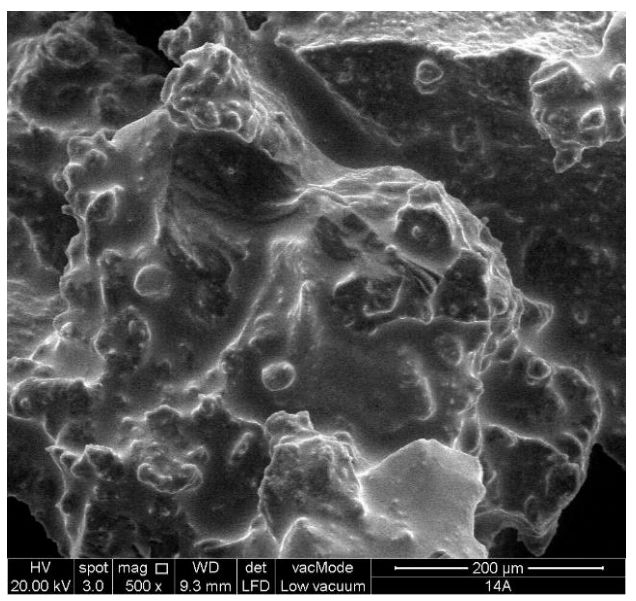

(n) 


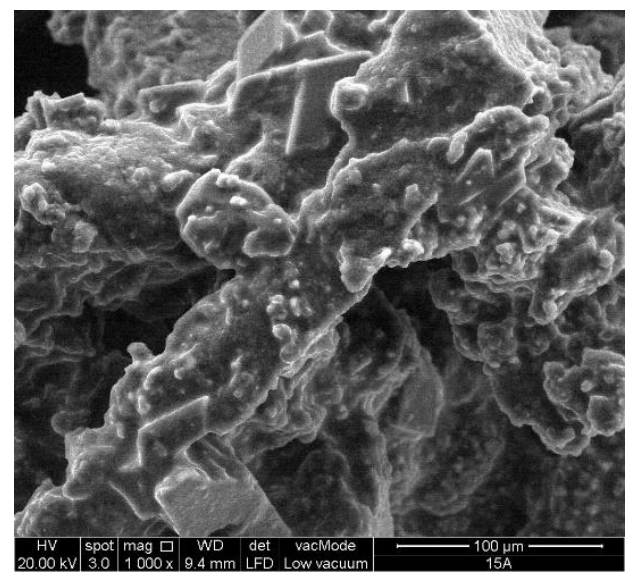

(o)

Fig. 11. FESEM analysis on rubber sample (a) 1A, (b) $2 \mathrm{~A}$, (c) $3 \mathrm{~A}$, (d) $4 \mathrm{~A}$, (e) $5 \mathrm{~A}$, (f) $6 \mathrm{~A}$, (g) $7 \mathrm{~A}$, (h) $8 \mathrm{~A}$, (i) $9 \mathrm{~A}$, (j) $10 \mathrm{~A}$, (k) $11 \mathrm{~A}$, (l) $12 \mathrm{~A}$, (m) $13 \mathrm{~A}$, (n) $14 \mathrm{~A}$ and (o) $15 \mathrm{~A}$ for $\mathrm{ZnCl}_{2}:$ Urea at 2:7

Referring and comparing Figure 11a to $11 \mathrm{o}$, the morphology of the samples were evaluated. Along with sample $1 \mathrm{~A}, 2 \mathrm{~A}, 3 \mathrm{~A}, 4 \mathrm{~A}$ and $5 \mathrm{~A}$ under mass ratio of 1:20, it can be noticed that Sample 2A as the smoothest surface out of all the other samples, followed by $1 \mathrm{~A}, 3 \mathrm{~A}, 4 \mathrm{~A}$ and finally $5 \mathrm{~A}$. From a microscopic view, it can be observed that sample $1 \mathrm{~A}$ is still rough in surface and stiff compared to sample $2 \mathrm{~A}$. From the micrograph, it is clearly seen that sample $1 \mathrm{~A}$ is still very rough and rigid in surface in comparison to sample $2 \mathrm{~A}$. Despite that sample $3 \mathrm{~A}$ has a similar surface as to sample $2 \mathrm{~A}$, hence the result tallies with EDX analysis result where the amount of sulphur removed is nearly similar. Such findings is said to be in equilibrium reformation for which if the heating temperature is more than optimum temperature, bond reformation will occur. A perfect example is sample $3 \mathrm{~A}$. Furthermore, small particles can been on top of the surface of the rubber sample. This could be due to contamination or left over of DES solution.

With sample 6A, 7A, 8A, 9A and 10A under mass ratio of 1:30, it can be shown clearly that sample 7A has the smoothest surface out of all the other samples, followed by $6 \mathrm{~A}, 8 \mathrm{~A}$, 9A and finally 10A. Sample 7A has almost similar surface area to sample 5A. Hence, it is presumed that both these samples will have similar characteristics as shown in EDX analysis whereby the percentage of sulphur removal is almost the same.

For sample $11 \mathrm{~A}, 12 \mathrm{~A}, 13 \mathrm{~A}, 14 \mathrm{~A}$ and $15 \mathrm{~A}$, under the mass ratio of $1: 40$, it can be observed clearly that sample $12 \mathrm{~A}$ has the smoothest surface out of all the samples since its surface is less rigid compared to others. Similar deduction is made for which the optimum heating temperature for devulcanisation is $130^{\circ} \mathrm{C}$.

All of the respective figures shown above for morphology structure, neither of the figures showed any failure, damage on quality on the rubber samples. This indirectly comes to conclusion that devulcanised rubber properties are maintained without destroying the backbone chain of the rubber and the results is in agreement with FTIR result.

\subsubsection{Soluble content analysis}

Gel content samples were carried out and determined in accordance to ASTM D2765 [42].The degree of devulcanisation process of the sample rubber was determined by obtaining the soluble and gel fraction through Soxhlet extraction apparatus using boiling 
toluene. Then, the samples were collected and immediately dried inside an oven at a temperature of $70^{\circ} \mathrm{C}$ once a steady mass was obtained. Hence, the lower the content of the gel, the higher the efficiency of the devulcanisation process [21]. Soluble fraction is determined from the following equation;

$$
\text { Soluble Content }=\left[\left(\mathrm{Wo}_{\mathrm{i}}-\mathrm{W}_{\mathrm{i}}\right) / \mathrm{Wo}\right] \times 100 \%
$$

Whereby, Wo is dry weight of devuclanised rubber before extraction process and $\mathrm{W}_{\mathrm{i}}$ is dry weight of devulcanised rubber after extraction process. From there, the gel fraction is determined from the expressed equation. The following Table 6 and 7 show the gel content analysis tabulation and the analysis was thoroughly discussed.

Table 6. Gel content analysis on rubber treated with 2:7 molar ratio of $\mathrm{ZnCl}_{2}$ :Urea

\begin{tabular}{|c|c|c|c|c|c|c|c|}
\hline Sample & Wo & $\mathbf{W}_{\mathrm{i}}$ & $\begin{array}{c}\text { Soluble fraction } \\
(\%)\end{array}$ & Sample & Wo & $\mathbf{W}_{\mathbf{i}}$ & $\begin{array}{c}\text { Soluble fraction } \\
(\%)\end{array}$ \\
\hline $1 \mathrm{~A}$ & 0.7276 & 0.7437 & 102.2127543 & $9 \mathrm{~A}$ & 0.8875 & 0.8448 & 95.18873239 \\
\hline $2 \mathrm{~A}$ & 0.6779 & 0.6788 & 100.1327629 & $10 \mathrm{~A}$ & 0.7573 & 0.741 & 97.84761653 \\
\hline $3 \mathrm{~A}$ & 0.8463 & 0.8252 & 97.50679428 & $11 \mathrm{~A}$ & 0.8667 & 0.7962 & 91.86569747 \\
\hline $4 \mathrm{~A}$ & 0.8647 & 0.8505 & 98.35781196 & $12 \mathrm{~A}$ & 0.8865 & 0.8518 & 96.0857304 \\
\hline $5 \mathrm{~A}$ & 0.9188 & 0.8171 & 88.93121463 & $13 \mathrm{~A}$ & 0.8565 & 0.7715 & 90.07589025 \\
\hline $6 \mathrm{~A}$ & 0.8801 & 0.8182 & 92.96670833 & $14 \mathrm{~A}$ & 0.8659 & 0.783 & 90.42614621 \\
\hline $7 \mathrm{~A}$ & 0.8069 & 0.7198 & 89.20560169 & $15 \mathrm{~A}$ & 0.9059 & 0.8201 & 90.52875593 \\
\hline $8 \mathrm{~A}$ & 0.8681 & 0.8487 & 97.76523442 & & & & \\
\hline
\end{tabular}

With respect to Table 6 , the trend that can be seen is that from sample $5 \mathrm{~A}$ to $1 \mathrm{~A}$, soluble fraction increases whereby sample $1 \mathrm{~A}$ has the highest soluble fraction. Next, from sample $10 \mathrm{~A}$ to $6 \mathrm{~A}$, it can be seen that the highest soluble fraction is achieved by sample $8 \mathrm{~A}$. And lastly, from sample $15 \mathrm{~A}$ to $11 \mathrm{~A}$, similar observation is seen where sample $12 \mathrm{~A}$ has the highest soluble fraction. High percentage of soluble fraction declares the fact that devulcanisation is efficient and it was experienced by sample 1A, $8 \mathrm{~A}$ and $12 \mathrm{~A}$. These results are tally with FTIR, TGA and EDX results earlier.

In a similar manner, observation from Table 7 shows that from sample $5 \mathrm{~B}$ to $1 \mathrm{~B}$, soluble fractions are approximately the same but sample $3 \mathrm{~B}$ has the highest value. Next, in between sample $10 \mathrm{~B}$ to $6 \mathrm{~B}$, sample $7 \mathrm{~B}$ and $9 \mathrm{~B}$ are on par in having the highest value. Lastly, from sample $15 \mathrm{~B}$ to $11 \mathrm{~B}$, it is clear that sample 13B has the highest soluble fraction. Thereby, treatment by $\mathrm{ZnCl}_{2}:$ Urea at $1: 4$ shows that the highest degree of devulcanisation was experienced by sample $3 \mathrm{~B}, 7 \mathrm{~B}$ and $9 \mathrm{~B}$ as well as $13 \mathrm{~B}$ which again tally with previous TGA, FTIR and EDX results.

Table 7. Gel content analysis on rubber treated with 1:4 molar ratio of $\mathrm{ZnCl}_{2}$ :Urea

\begin{tabular}{|c|c|c|c|c|c|c|c|}
\hline Sample & $W_{0}$ & $\mathbf{W}_{\mathrm{i}}$ & $\begin{array}{c}\text { Soluble fraction } \\
(\boldsymbol{\%})\end{array}$ & Sample & $\mathbf{W o}_{\mathrm{o}}$ & $\mathbf{W}_{\mathrm{i}}$ & $\begin{array}{c}\text { Soluble fraction } \\
(\%)\end{array}$ \\
\hline
\end{tabular}




\begin{tabular}{|c|c|c|c|c|c|c|c|}
\hline $1 \mathrm{~B}$ & 0.8582 & 0.834 & 97.18014449 & $9 \mathrm{~B}$ & 0.8994 & 0.8686 & 96.57549477 \\
\hline $2 \mathrm{~B}$ & 0.8802 & 0.8577 & 97.44376278 & $10 \mathrm{~B}$ & 0.9056 & 0.8176 & 90.28268551 \\
\hline $3 \mathrm{~B}$ & 0.8645 & 0.8562 & 99.03990746 & $11 \mathrm{~B}$ & 0.8865 & 0.7762 & 87.55781162 \\
\hline 4B & 0.7617 & 0.7445 & 97.74189313 & $12 \mathrm{~B}$ & 0.8376 & 0.8069 & 96.334766 \\
\hline $5 \mathrm{~B}$ & 0.8975 & 0.8714 & 97.09192201 & $13 \mathrm{~B}$ & 0.9141 & 0.9039 & 98.88414834 \\
\hline $6 \mathrm{~B}$ & 0.8654 & 0.7756 & 89.62329559 & 14B & 0.8686 & 0.7829 & 90.13354824 \\
\hline $7 \mathrm{~B}$ & 0.8817 & 0.8499 & 96.39333106 & $15 \mathrm{~B}$ & 0.8641 & 0.7941 & 91.89908575 \\
\hline $8 \mathrm{~B}$ & 0.8821 & 0.8251 & 93.5381476 & & & & \\
\hline
\end{tabular}

\section{Conclusion}

DES as an alternative to IL was utilized to devulcanise rubber tyre due to its property of being cheap, non-toxic and biodegradable. Amino-compound-based deep eutectic solvents were chosen as they have been proven to be efficient in attracting sulphur in desulphurisation process. Particularly in this study, $\mathrm{ZnCl}_{2}$ : Urea DES was chosen and its molar ratio was varied to $1: 4$ and 2:7. Characterisation found that their moisture contents are below the maximum allowable limit with freezing point of $<60^{\circ} \mathrm{C}$ and degradation temperature that is higher than $200^{\circ} \mathrm{C}$.

Rubber tyre were then treated with $\mathrm{ZnCl}_{2}$ :Urea DES at 1:20, 1:30 and 1:40 mass ratios (rubber:DES) at variable temperature of $30,130,150$ and $180^{\circ} \mathrm{C}$. Finding shows that the optimum heating temperature is at $130^{\circ} \mathrm{C}$ for devulcanisation process for treatment with $\mathrm{ZnCl}_{2}$ :Urea (2:7). And when the temperature were increased to higher than $130^{\circ} \mathrm{C}$, it was observed that decrease in devulcanisation efficiency and bond reformation took place, which allowing removed sulphur re-bonded back to carbon backbone by utilising free electrons. Therefore, it is important to stop at the optimum temperature in order to avoid bond reforming from occurring and to also ensure the maximum removal of sulphur content from the rubber sample mixture. FESEM analysis showed that most samples at $130^{\circ} \mathrm{C}$ gives the smoothest surface of rubber sample thus indicating the devulcanisation process was a success. In addition, FTIR analysis showed that $-\mathrm{S}-\mathrm{S}$ - bond is the only bond which was cleaved during the process which proves a successful devulcanisation. On the other hand, for samples treated with $\mathrm{ZnCl}_{2}$ :Urea (1:4), high degree devulcanization is achieved at temperature $>130^{\circ} \mathrm{C}$. Thereby, indeed DES has great capability in devulcanising tyre.

\section{References}

1. O. E. Ikwuagwu, I. C. Ononogbu, and O. U. Njoku, "Production of biodiesel using rubber seed oil," vol. 12, pp. 57-62, 2000.

2. S. Rooj, G. C. Basak, P. K. Maji, and A. K. Bhowmick, "New Route for Devulcanization of Natural Rubber and the Properties of Devulcanized Rubber," $J$. Polym. Environ., vol. 19, no. 2, pp. 382-390, 2011. 
3. P. J. H. van Beukering and M. A. Janssen, "Trade and recycling of used tyres in Western and Eastern Europe," Resour. Conserv. Recycl., vol. 33, no. 4, pp. 235265, 2001.

4. M. Sienkiewicz, J. Kucinska-Lipka, H. Janik, and A. Balas, "Progress in used tyres management in the European Union: A review," Waste Manag., vol. 32, no. 10, pp. 1742-1751, 2012.

5. S. Ramarad, M. Khalid, C. T. Ratnam, A. L. Chuah, and W. Rashmi, "Waste tire rubber in polymer blends: A review on the evolution, properties and future," Prog. Mater. Sci., vol. 72, pp. 100-140, 2015.

6. A. Joseph, B. George, M. K N, and R. Alex, "The Current Status of Sulphur Vulcanization and Devulcanization Chemistry," Rubber Sci., vol. 29, no. 1, pp. 62$100,2016$.

7. K. Bredberg, B. Erik Andersson, E. Landfors, and O. Holst, "Microbial detoxification of waste rubber material by wood-rotting fungi," Bioresour. Technol., vol. 83, no. 3, pp. 221-224, 2002.

8. a. Zanchet, L. N. Carli, M. Giovanela, J. S. Crespo, C. H. Scuracchio, and R. C. R. Nunes, "Characterization of Microwave-Devulcanized Composites of Ground SBR Scraps,” J. Elastomers Plast., vol. 41, no. 6, pp. 497-507, 2009.

9. X. Zhang, C. Lu, and M. Liang, "Properties of natural rubber vulcanizates containing mechanochemically devulcanized ground tire rubber," J. Polym. Res., vol. 16, no. 4, pp. 411-419, 2009.

10. H. Wang et al., "Multifunctional $\mathrm{TiO} 2$ nanowires-modified nanoparticles bilayer film for 3D dye-sensitized solar cells," Optoelectron. Adv. Mater. Rapid Commun., vol. 4, no. 8, pp. 1166-1169, 2010.

11. V. V. Rajan, W. K. Dierkes, R. Joseph, and J. W. M. Noordermeer, "Science and technology of rubber reclamation with special attention to NR-based waste latex products," Prog. Polym. Sci., vol. 31, no. 9, pp. 811-834, 2006.

12. V. A. Online, "Deep eutectic solvents based on N -methylacetamide and a lithium salt as suitable electrolytes for lithium-ion batteries," no. 3, pp. 20054-20063, 2013.

13. G. Garcia, S. Aparicio, R. Ullah, and M. Atilhan, "Deep Eutectic Solvents: Physicochemical Properties and Gas Separation Applications," Energy \& Fuels, vol. 29, pp. 2616-2644, 2015.

14. Q. Zhang, K. De Oliveira Vigier, S. Royer, and F. Jérôme, "Deep eutectic solvents: syntheses, properties and applications," Chem. Soc. Rev., vol. 41, no. 21, p. 7108, 2012.

15. S. Seghar et al., "Devulcanization of styrene butadiene rubber by microwave energy: Effect of the presence of ionic liquid," Express Polym. Lett., vol. 9, no. 12, pp. 1076-1086, 2015.

16. C. Acids, C. Florindo, and A. M. Fernandes, "Insights into the Synthesis and Properties of Deep Eutectic Solvents Based on Cholinium Chloride," ACS Sustainable Chemistry Engineering, vol. 2, pp. 2416-2425, 2014.

17. A. I. Isayev, S. P. Yushanov, S.-H. Kim, and V. Y. Levin, "Ultrasonic Devulcanization of Waste Rubbers: Experimentation and modeling," Rheol. Acta, vol. 35, no. 6, pp. 616-630, 1996.

18. S. Seghar, N. A. Hocine, V. Mittal, S. Azem, B. Schmaltz, and N. Poirot, "Devulcanization of styrene butadiene rubber by microwave energy : Effect of the presence of ionic liquid," vol. 9, no. 12, pp. 1076-1086, 2015.

19. R. U. N. D. Anwendungen, "Devulcanization of Whole Passenger Car Tire Material," pp. 20-25, 2013. 
20. P. S. Garcia, F. D. B. De Sousa, J. A. De Lima, S. A. Cruz, and C. H. Scuracchio, "Devulcanization of ground tire rubber: Physical and chemical changes after different microwave exposure times," vol. 9, no. 11, pp. 1015-1026, 2015

21. F. Endres, D. McFariane and A. Abbot, Electrodeposition from Ionic Liquid, Germany: Wiley-VCH, 2008.

22. K. Shahbaz, F. S. Mjalli, M. A. Hashim, and I. M. AlNashef, "Prediction of deep eutectic solvents densities at different temperatures," Thermochimica Acta, vol. 515, pp. 67-72, 2011.

23. K. Aoudia, S. Azem, N. A. Hocine, M. Gratton, V. Pettarin, and S. Seghar, "Recycling of waste tire rubber: Microwave devulcanization and incorporation in a thermoset resin," Waste Manag., vol. 60, pp. 471-481, 2017.

24. A. I. Isayev and B. Sujan, "Nonisothermal vulcanization of devulcanized GRT with reversion type behavior," J. Elastomers Plast., vol. 38, no. 4, pp. 291-318, 2006.

25. E. T. Thostenson and T.-W. Chou, "Microwave processing: fundamentals and applications," Compos. Part A Appl. Sci. Manuf., vol. 30, no. 9, pp. 1055-1071, 1999.

26. C. Guo, L. Zhou, and J. Lv, "Effects of expandable graphite and modified ammonium polyphosphate on the flame-retardant and mechanical properties of wood flour-polypropylene composites," Polym. Polym. Compos., vol. 21, no. 7, pp. 449-456, 2013.

27. L. Landini, S. G. de Araújo, A. B. Lugão, and H. Wiebeck, "Preliminary analysis to BIIR recovery using the microwave process," Eur. Polym. J., vol. 43, no. 6, pp. 2725-2731, 2007.

28. V.YU.Levin, S.H.Kim, and A.I.Isayev, "Ultrasound Devulcanization of Sulfur Vulcanized SBR Crosslink Density and Molecular Mobility," Rubber Chemistry and Technology, vol. 69, no. 1.pp. 104-114, 1996.

29. A.Pelofsky, "Rubber reclamation using ultrasonic energy," US3725314 A, 1971.

30. M. Okuda and Y. Hatano, "Devulcanization of cured rubber," US5891926 A, 1998.

31. N. Senapati and D. Mangaraj, "Ultrasonic vulcanization," US4548771 A, 1984.

32. G. Garcia, S. Aparicio, R. Ullah, and M. Atilhan, "Deep Eutectic Solvents: Physicochemical Properties and Gas Separation Applications," Energy \& Fuels, vol. 29, pp. 2616-2644, 2015.

33. A. R. Ferreira, M. G. Freire, J. C. Ribeiro, F. M. Lopes, J. G. Crespo, and J. A. P. Coutinho, "Ionic liquids for thiols desulfurization: Experimental liquid-liquid equilibrium and COSMO-RS description," Fuel, vol. 128, pp. 314-329, 2014.

34. V. A. Online, "Deep eutectic solvents based on N -methylacetamide and a lithium salt as suitable electrolytes for lithium-ion batteries," no. 3, pp. 20054-20063, 2013 .

35. S. Seghar et al., "Devulcanization of styrene butadiene rubber by microwave energy: Effect of the presence of ionic liquid," Express Polym. Lett., vol. 9, no. 12, pp. 1076-1086, 2015.

36. Q. Zhang, K. De Oliveira Vigier, S. Royer, and F. Jérôme, "Deep eutectic solvents: syntheses, properties and applications," Chem. Soc. Rev., vol. 41, no. 21, p. 7108, 2012.

37. M. H. Chakrabarti et al., "Prospects of applying ionic liquids and deep eutectic solvents for renewable energy storage by means of redox flow batteries," Renew. Sustain. Energy Rev., vol. 30, pp. 254-270, 2014.

38. L. Bahadori, M. H. Chakrabarti, F. S. Mjalli, I. M. Alnashef, N. S. A. Manan, and M. A. Hashim, "Physicochemical properties of ammonium-based deep eutectic solvents and their electrochemical evaluation using organometallic reference redox systems," Electrochim. Acta, vol. 113, pp. 205-211, 2013. 
39. R. Saputra, "Devulcanization of Waste Rubber Tyre Utilizing Deep Eutectic Solvents and Ultrasonic Energy," Taylor's University Lakeside Campus, 2016.

40. S. Ghose and A. I. Isayev, "Recycling of unfilled polyurethane rubber using highpower ultrasound," J. Appl. Polym. Sci., vol. 88, no. 4, pp. 980-989, 2003.

41. T. Liang, "Continuous Devulcanization of Ground Tire Rubber of Different Particle Sizes Using an Ultrasonic Twin-Screw Extruder," 2013.

42. S. Ramarad, C. T. Ratnam, M. Khalid, A. L. Chuah, and S. Hanson, "Improved crystallinity and dynamic mechanical properties of reclaimed waste tire rubber/EVA blends under the influence of electron beam irradiation," Radiat. Phys. Chem., vol. 130, pp. 362-370, 2017. 